\title{
Die Schnecken (Gastropoda Prosobranchia) der deutschen Meeresgebiete und brackigen Küstengewässer
}

\author{
ERICH Ziegelmeier \\ Biologische Anstalt Helgoland, Litoralstation, List auf Sylt
}

\begin{abstract}
The snails (Gastropoda Prosobranchia) of the German marine areas and brackish coastal waters. Following a systematic treatment of the Bivalvia (ZieGeLMEIER 1957), this paper presents a taxonomic survey of the Gastropoda species found in marine and coastal waters near Germany; it includes species known from other countries bordering the North Sea and Baltic Sea. Employing taxonomic keys and numerous photographic illustrations, determinations are based on shell structures. Definitions of technical terms and explanations of pertinent details of gastropod anatomy are given in order to make determinations possible also for beginning students and interested laymen.
\end{abstract}

\section{EINLEITUNG}

Zu den wichtigsten und auffälligsten Wirbellosen-Gruppen unserer Meeresgebiete gehören die Mollusken, besonders die Muscheln (Bivalvia) und Schnecken (Gastropoda). Noch lange nach dem Verenden der Tiere sind deren Lebensspuren in Form der übrigbleibenden Hartgebilde vorhanden, die entweder im Angespül am Strand liegen, oder aus gebaggertem und gedretschtem Benthosprobenmaterial gesammelt werden können. In den meisten Fällen lassen auch die leeren Schalen und Gehäuse die Artzugehörigkeit erkennen.

Die Hauptmasse der Weichtier-Lebensbestände bilden in unserem Gebiet die Muscheln. Die Schnecken, obwohl sie zur artenreichsten Klasse der Mollusken gehören, spielen mengen- und artenmäßig eine geringere Rolle. So konnten zum Beispiel während der quantitativen und qualitativen Bodenfaunauntersuchungen im Ostteil der Deutschen Bucht in der Zeit von 1949 bis 1960 (Ziegelmeier 1963) 38 Muschel- und nur 8 Schneckenarten (lebende Individuen) festgestellt werden. In diesen Zahlen sind jedoch nicht die Spezies des Felswatts bei Helgoland und der sandigen bis schlickigen Wattgebiete an der Küste enthalten. Es ergäben sich dann 51 Muschel- und 25 Schnekkenarten. ANkel (1936) zählt 27 Gastropodenspezies für die Deutsche Bucht, einschließlich Helgoland auf. HeINCKe (1894) nennt 40, von denen aber nur 29 als "lebend beobachtete Arten " bezeichnet, die übrigen "nur in leeren Schalen" gefunden wurden. Für Helgoland führt Heincke 65 Muschelarten an, von denen 45 als lebend vorkommend gelten. Wir erhalten demnach für die deutschen Nordseegebiete ein quantitatives Artenverhältnis Muscheln zu Schnecken von annähernd 2:1. Für unsere 
Ostseegebiete betragen die entsprechenden Werte etwa 1,5:1, wobei allerdings sämtliche Brackwasserformen mitgerechnet wurden.

Nachdem die Muscheln systematisch bearbeitet wurden (ZIEGELMEIER 1957) mit dem Ziel, eine Bestimmung nach Schalenmerkmalen zu ermöglichen, werden hier in gleicher Weise die Schneckenarten zusammengestellt, die wir in unseren Meeresteilen und brackigen Küstengewässern finden können. Da jedoch mit Verdrifung, Einschleppung durch die Fischerei sowie mit sonstigen Transportmöglichkeiten zu rechnen ist, sind die Küstengebiete der anderen Anliegerstaaten im Gebiet der südlichen, mittleren und nördlichen Nordsee einbezogen worden. Dies bedeutet aber nicht, daß sämtliche in den erwähnten Nachbargebieten bisher nachgewiesenen Schneckenarten (lebende Individuen oder leere Gehäuse) aufgeführt sind. Mit Hilfe einer Bestimmungstabelle und zahlreichen photographischen Aufnahmen ${ }^{1}$ soll die vorliegende Darstellung ermöglichen, auch die Schnecken nach ihren Schalenmerkmalen zu determinieren.

\section{BESTIMMUNG NACH DEN SCHALENMERKMALEN}

Die Form des Schneckengehäuses ergibt sich aus der spiraligen Einrollung des Eingeweidesackes, die wohl bei der hypothetischen Ausgangsform, nach vorn gerichtet, einen symmetrischen Bau ergab. Eine im Verlauf der Stammesgeschichte erfolgte Drehung um $180^{\circ}$, die sich auch ontogenetisch beobachten läßt, deren eigentliche Ursachen jedoch umstritten sind und hier nicht weiter diskutiert werden können, verlagerte die Mantelhöhle nach vorn und einige Organe auf die entgegengesetzten Seiten; dabei erfolgte die Uberkreuzung der Schenkel der beiden Visceralschlingen (Streptoneurie, Chiastoneurie). Organrückbildungen, Reduktion, beziehungsweise Verschwinden der ursprünglich linken, nach der Torsion rechten Kieme, die dadurch vor dem Herzen zu liegen kommt, führten zum asymmetrischen Bau der Vorderkiemerschnekken, der Gastropoda P r o s obra n chia (Unterklasse Streptoneura). Ihr Körper ist gegliedert in Fuß (Kriechsohle), Kopf und Eingeweidesack mit Mantel, dessen Epithel die $\mathrm{S} \mathrm{ch}$ a l e ausscheidet.

Die Schale besteht, wie die der Bivalven, zum größten Teil (bis zu $98 \%$ ) aus Calciumkarbonat (beziehungsweise Aragonit), zum geringeren aus Conchiolin (etwa $1,5 \%$ ). In ihrer Struktur ist die Schneckenschale ebenfalls meist dreischichtig mit einer äußeren Conchiolinhaut, dem Periostrakum, einer porzellanartigen $\mathrm{Sch}$ icht, die wiederum aus mehreren Prismen-Lagen zusammengesetzt ist und bei den ältesten Gruppen mit einer inneren Per $1 \mathrm{~m} u t \mathrm{t}$ e $\mathrm{s} c \mathrm{~h}$ i $\mathrm{cht}$.

1 Für die freundliche Uberlassung von Schneckenschalen zur Herstellung der photographischen Aufnahmen möchte ich an dieser Stelle herzlichst danken: Prof. Dr. W. SCHÄFER und Dr. A. ZILCF, Natur-Museum und Forschungs-Institut, "Senckenberg", Frankfurt/Main; Prof. Dr. G. Trorson, Dr. K. W. OCKELMANN, Marinbiologisk Laboratorium, Grønnehave, Helsingør; Dr. G. HøpNer PETERsen, Universitetets Zoologiske Museum, København; Prof. Dr. W. E. Ankel, Dr. Götring und Dr. Kaufmann, Zoologisches Institut, Gießen; Dr. Orm, Zoologisches Institut, Kiel; Dr. N. TEBbLE, British Museum (Natural History) London; Dr. D. A. Hancock, Ministery of Agriculture, Fisheries and Food, Fisheries Laboratory, Burnham-onCrouch, Essex; Dr. Den Hartog, Leiden, Holland, und Dr. S. Jaecker, Kiel. 
Der spiralige Gehäusetyp ist bei den prosobranchen Gastropoden der häufigste; kappen-, napf- und röhrenförmige Schalen können sämtlich auf einen spiraligen Bauplan zurückgeführt werden. Die Windungen (Umgänge, Anfractus) liegen entweder in einer Ebene (planspiral), oder steigen mit mannigfachen Abwandlungen flach, steil bis turmförmig spitz auf (turbospiral), sie sind durch die mehr oder weniger tief eingeschnittene $\mathrm{Naht}$ (Sutura) gegeneinander abgesetzt (Abb. 1 und 2).

Die Anzahl der Windungen ist sehr verschieden, innerhalb einer Art aber mehr oder weniger konstant. Berühren sich die Ungänge nicht und bilden eine freistehende lose Spirale, so bezeichnen wir das Gehäuse als d e v o lu $t$ (in unserer Fauna ist dies zum Teil bei Capulus der Fall, Taf. 16, 1). Liegen die Windungen aneinander ( e v olu t; die häufigsten Formen) und berühren sich die Umgänge derart, daß von den älteren Windungen eben noch etwas zu erkennen ist, so sprechen wir von einem k o n v o 1 u t e n Gehäuse (Beispiel: Littorina obtusata, Taf. 10, 1). Umfassen sich die Windungen auch seitlich, wobei nur noch der jüngste Umgang zu sehen ist, so erhalten wir eine in vol u te Schale (Beispiel: Trivia, Taf. 15, 2).

Der älteste Teil des Gehäuses ist die Spitze oder A pex mit dem Embryonalgewinde, das mitunter eine andere Windungsrichtung haben kann. Der jüngste Schalenteil ist der Rand der $M$ ündung, durch die das Tier die Kriechsohle herausstreckt und wieder zurückzieht (Abb. 1).

Bei einigen Arten zichen sich die Schnecken während des Wachstums aus den älteren Umgängen zurück und schließen diese durch eine Querwand ab. Häufig werden die leeren Erstwindungen abgestoßen. Dieser Vorgang kann sich wiederholen und so zu einer Schalenform wie bei Caecum führen (Abb. 3). Die Windungen in ihrer Gesamtheit von der Spitze bis zum Ende der Naht (an der Nahtecke auf dem letzten Umgang) werden als $\mathrm{G}$ e w in de (Spira) bezeichnet (Abb. 1).

Liegen die Umgänge mit ihren inneren Wandungen aneinander, so bildet sich eine solide Säule, die S p in d el (Columella); berühren sie sich nicht, so entsteht ein nach oben enger werdender Hohlraum, die $\mathrm{Nabelhöhle,} \mathrm{die} \mathrm{äußerlich} \mathrm{am}$ $\mathrm{Nabel}$ (Umbilicus) zu erkennen ist (Abb. 7 und 5). Die gedachte Linie vom Apex durch die Columella (Vollspindel) oder Nabelhöhle (Hohlspindel) bis zum unteren Mündungsrand ist die A c h s e, die Schalenhöhe; der größte Durchmesser des letzten Umganges ist die Breite des Gehäuses.

Mit nur wenigen Ausnahmen (in unserer Fauna Triphora perversa, Taf. 11, 2) sind die Schalen $\mathrm{rech}$ ts g e w u n d e $\mathrm{n}$, das heißt die Umgänge verlaufen bei Blickrichtung auf den Apex im Uhrzeigersinn. Bei der richtigen Orientierung der Schale mit der Spitze nach oben, Mündung nach unten und auf den Beschauer zugekehrt, befindet sich die Mündung bei rechtsgewundenen Gehäusen rechts von der Achse und bei linksgewundenen Gehäusen links von der Achse.

Die äußere Begrenzung der Mündung ist der $\mathrm{Mund}$ rand, der vielgestaltig sein kann und für die Bestimmung wertvolle diagnostische Merkmale liefert. Seine Form ist mannigfaltig und variiert von einer fast kreisrunden bis $\mathrm{zu}$ einer spaltartigen Offnung. Die Dicke des Mundrandes ist sehr verschieden; er kann durch besondere Anwachsstreifen bei Unterbrechung der Wachstumszunahme des letzten Umganges beträchtlich verstärkt werden (Varices); er kann innen glatt, gezähnt oder gerippt, außen mit Wülsten, Stacheln oder mehr oder weniger langen Dornen versehen 
sein; er kann aber auch einen dünnwandigen Mundsaum bilden. Nur bei erwachsenen Schnecken ist der Mundrand arttypisch ausgebildet, wie zum Beispiel die flügelartig erweiterte Außenlippe bei Aporrbais (Taf. 16, 2 a bis c). Wir unterscheiden beim Mundrand $A \mathrm{u} B$ en rand, oder Außenlippe und Innen rand, oder Innenlippe. Die Lippen können oben und unten so ineinander übergehen, daß ein zusammenhängender, freistehender Rand gebildet wird, der die Wandung des letzten Umganges nicht berührt (Taf. 9, 1 a). In den meisten Fällen jedoch sind Außen- und Innenrand mehr oder minder deutlich gegeneinander abgesetzt, entweder nur oben an der Stelle, an welcher der Außenrand auf die Wandung des letzten Umgangs trifft (Ende der Nahtlinie, Nahtecke; Abb. 1), oder durch die Nahtecke und den - bei phylogenetisch jüngeren Gruppen - am unteren Mundrand ausgebildeten Kanal für den Sipho des lebenden Tieres, die Siphonalrinne (Abb. 6).

Bei stammesgeschichtlich älteren Gruppen befindet sich etwa in der Mitte des Außenrandes ein $\mathrm{S}$ chlitz, der während des Schalenwachstums geschlossen wird und nach den älteren Windungen hin als Schlitzband zu erkennen ist (Taf. 1, 1 b). Die kappenförmigen Fissurellidae zeigen den Schlitz entweder am Schalenvorderrand oder als schlitzartige Offnung vor dem Apex (Taf. 1, 2 und 3).

Während die Rundung des Außenrandes ein einheitliches Aussehen zeigt (Palatalund Basalrand gehen meist undeutlich ineinander über - abgesehen von den Arten mit Syphonalrinne), ist der Innenrand der Mündung häufig verschieden gestaltet. Der Innenrand kann fast ganz fehlen (Taf. 12, 3); er wird dann durch die Wandung des letzten Umganges (Parietalrand) ersetzt. In den meisten Fällen läßt sich beim Innenrand ein oberer parie ta le r von dem colu mell a re n Abschnitt (Spindelrand), der vom unteren Ende der Spindel gebildet wird, unterscheiden (Abb. 1). Nicht selten sind auf dem Parietal- und dem Spindelrand Zähnchen, Lamellen oder Falten ausgebildet.

Ebenso wichtig wie das Aussehen der Mündung ist für die Bestimmung die Oberfläche der Umgänge. Sie können glatt oder skulptiert sein. Die verschiedensten Formen von Wülsten, Knoten, Reifen, Zacken, Stacheln, Vertiefungen und Erhöhungen sind meist so angeordnet, daß sie entweder in Richtung des Wachstums der Umgänge

\section{Abbildung 1-7}

Abb. 1 und 2: Turbospirale Schneckenschale (etwas schematisiert); Mündungs- beziehungsweise Rückansicht. - Abb. 3: Schematische Darstellung der Schalenentwicklung bei Caecum glabrum MoNTAGU. Vor Abwerfen des Embryonalgewindes (Eg) wird die erste Scheidewand $\left(S_{1}\right)$ gebildet. Während des Gehäusewachstums kommt es zum Abstoßen eines weiteren Schalenstückes, nach dem durch eine zweite Scheidewand $\left(S_{2}\right)$ das verbleibende Gehäuse verschlossen wird. (Nach ANKEL 1936, etwas umgezeichnet). - Abb. 4: Gehäuse von Lunatia catena DA CosTA (schematisch) mit Nabel. - Abb. 5: Querschliff durch die Achse der Schale von Lunatia catena zur Darstellung der typischen Nabelhöhle (Hohlspindel). - Abb. 6: Schale von Buccinum undatum LiNNé mit Siphonalrinne. - Abb. 7: Querschliff durch ein Gehäuse von Buccinum undatum zur Veranschaulichung der Columella (Vollspindel).

Die Abkürzungen bedeuten: A: Apex (Spitze), Ah: Achse, die Höhe des Schneckengehäuses, Ar: Außenrand der Mündung, Br: Basalrand, Co: Columella, Gew: Gewinde, Gi: Gitterskulptur, L: Leisten, Mdg: Mündung, N: Naht, Na: Nabel, Ne: Nahtecke, Nh: Nabelhöhle, Palr: Palatalrand, Par: Parietalrand, Ri: Rippen, Si: Siphonalrinne, Spr: Spindelrand, Um: Umgänge. 
Schnecken deutscher Meeresgebiete und Küstengewässer
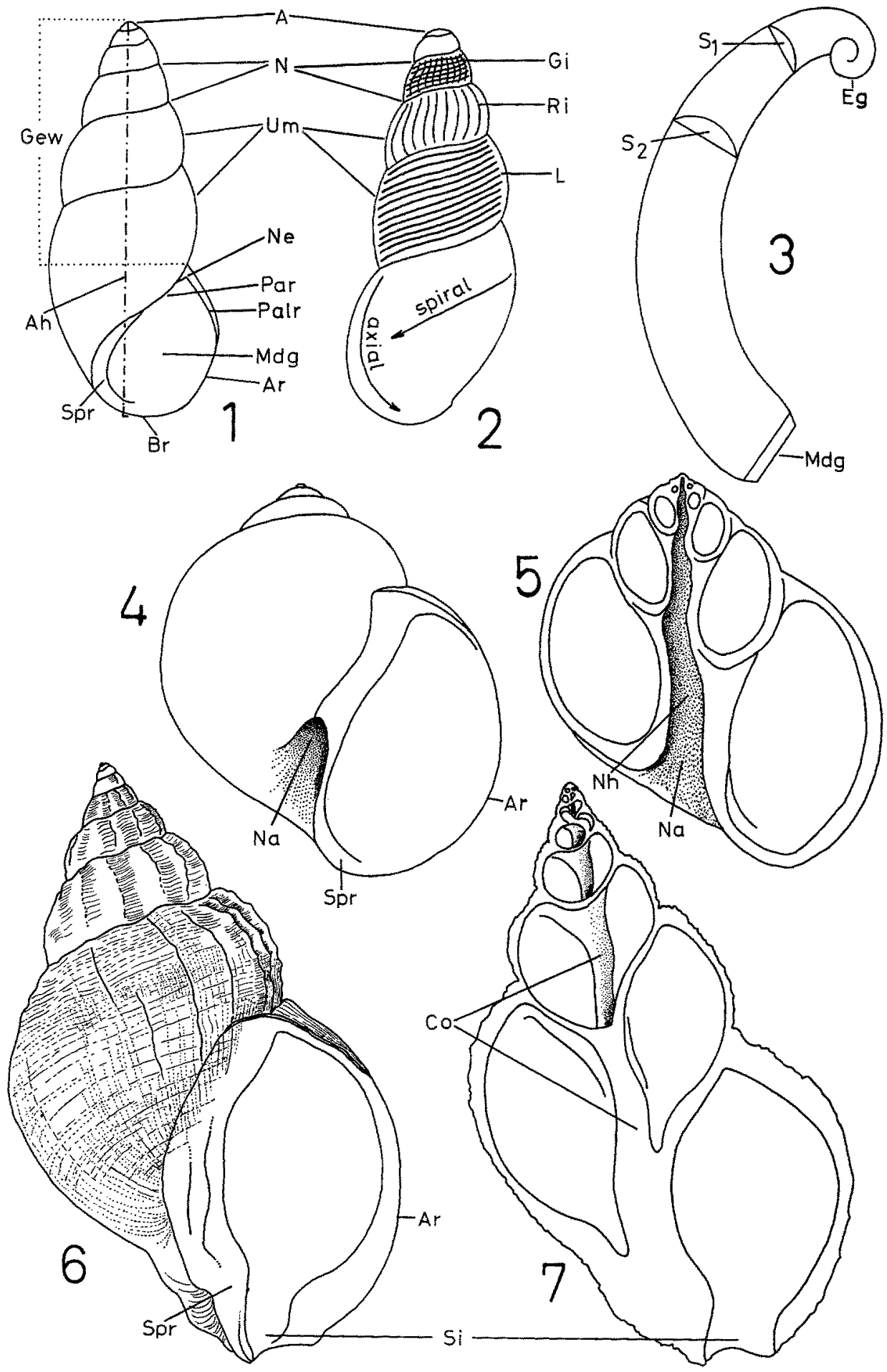
(spiral), oder senkrecht dazu, also in Richtung der Zuwachsstreifen, parallel zum Mündungsaußenrand (axial) verlaufen (Abb. 2). Bei planspiralen oder flachen Gehäusen wird die axiale zur radiären Skulptur. Spirale Anordnung von Reifen oder Kielen bezeichnet man als $L$ e is $\tau$ e $n$, axiale als $R$ i p pen, beide zusammen ergeben eine Git te rskulptur (Abb. 2). Kappen- und napfförmige Gehäuse sind radiär oder (und) konzentrisch skulptiert.

Obgleich bei den Schneckenschalen durch die Mannigfaltigkeit ihrer Formen gute artdiagnostische Merkmale vorhanden sind, reichen mitunter die Schalenmerkmale allein für die genaue Bestimmung nicht aus. Der Grund hierfür ist die, im Vergleich zu den Muscheln, stärker ausgeprägte Tendenz der Prosobranchier zur Varietätenbildung, deren Ursache Ankel (1936) "vor allem in der Empfindlichkeit des Schalenbildungsvorganges" sieht. Häufig treten Standortmodifikationen besonders bei den Arten auf, die zur Epifauna gehören, zum Beispiel Littorina, Buccinum, Nucella. Von den Außenfaktoren, die Schalenveränderungen verursachen, spielt - neben der Wasserbewegung (Brandung auf felsigem Untergrund oder flachem Sandstrand) - der Salzgehalt eine wichtige Rolle. So sind im allgemeinen die in der Ostsee lebenden Arten kleiner und dünnschaliger als die entsprechenden Nordseeformen.

Als weiteres Hilfsmittel bei der Bestimmung von Schnecken wird der Mündungsverschluß oder Deckel (Operculum) benutzt, der in den meisten Fällen hornig, seltener kalkig ist. Die Form des Deckels, die sich meist mit derjenigen der Schalenmündung deckt, die konzentrische oder spirale Skulptur der Außenseite sowie die Lage des Wachstumszentrums (Nucleus) ergeben vielfach gute artdiagnostische Merkmale.

Für die eindeutige Artbestimmung kommt dem Schneckengebiß, der Zunge (Radula), besondere Bedeutung zu. Die in Querreihen auf der bandförmigen Basalmembran bilateralsymmetrisch angeordneten einzelnen Glieder, die aus chitinigen Zähnchen und Platten bestehen, sind in ihrer Anzahl und ihrem Bau untereinander völlig gleich und wegen ihrer Formkonstanz für die Systematik besonders wertvoll.

Die natïrlichsten Hauptgruppen der prosobrandhen Schnecken basieren auf Form und Anzahl der Kiemen, Herzvorkammern und vor allem auf der Beschaffenheit der Radula. 
Klasse:

Gastropoda (Schnecken)

Unterklasse: Amphigastropoda
$\begin{gathered}\text { Prosobranchia } \\ \begin{array}{c}\text { (Streptoneura, } \\ \text { Gekreuztnervige) } \\ \text { Vorderkiemer }\end{array}\end{gathered}$

\section{Ordnung:}

Gehäuse von verschiedener Gestalt, kappen-, napf-, kreisel- bis kegelförmig, turbospiral, zum Teil mit Schlitz am Mündungsaußen- beziehungsweise am Vorderrand (bei kappenförmigen) oder vor dem Apex. Schale meist m it Perlmutterschicht (Taf. 1 bis 5, 2). . . . . . . . . . . . ARCHAEOGASTROPODA (S. 7)

Diotocardia (2 Herzvorhöfe, häufig auch noch 2 Kiemen und

2 Nieren, bei einigen Formen rechte Kieme und linke Niere rückgebildet)

Rhipidoglossa (Fächerzüngler)

Dokoglossa (Balkenzüngler)

II. Ordnung:

Schale o h n e Perlmutterschicht, Gehäuseform sehr verschieden, meist turbo-, mitunter planspiral (Taf, 5, 3 bis 16,2) . . . . . . . MESOGASTROPODA (S. 10)

Monotocardia (1 Herzvorhof, 1 Kieme, 1 Niere)

Taenioglossa (Bandzüngler)

III. Ordnung:

Schalenmündung unten mit einer verschieden langen Siphonalrinne (Taf. 17 bis 20)

NEOGASTROPODA (S. 18)

Stenoglossa (Engzüngler)

ARCHAEOGASTROPODA

\section{Scissurellidae \\ Scissurella A. ORBIGNY}

Gehäuse klein, weiß, dünnschalig, innen schwach perlmuttrig. Gewinde niedrig. Gitterskulptur, axiale etwas stärker hervortretend. Endwindung groß, genabelt. In der Mitte des Mündungsaußenrandes ein offener Schlitz, der sich als geschlossenes Schlitzband mit kielartig erhobenen Rändern auf der Mitte der Umgänge fortsetzt (bis $2 \mathrm{~mm}$ hoch und $3 \mathrm{~mm}$ breit) . . . . . . . . Scissurella crispata (Taf. 1, 1 a bis c) 
Fissurellidae

Schale kappen- beziehungsweise napfförmig, meist bilateralsymmetrisch und mit feinerer oder gröberer Gitterskulptur. Entweder mit Schlitz vom Vorderrand aus oder mit schlitzförmiger Ơffnung vor dem Apex, mitunter an seine Stelle tretend.

\section{Emarginula LAMARCK}

Gehäuse farblos, kappenförmig mit Gitterskulptur, wobei die radiären Rippen stärker ausgebildet sind. Apex nach hinten verlagert. Vom Schalenvorderrand aus ein offener Schlitz mit anschließendem Schlitzband zwischen 2 Radiärrippen. Innen glatt und ohne Septum (bis $10 \mathrm{~mm}$ lang und bis $4 \mathrm{~mm}$ breit) Emarginula fissura (Taf. 1,2 a bis c)

\section{Puncturella R. T. Lowe}

Schale kappenförmig, kräftig radiär skulptiert und fein konzentrisch gekörnelt. Apex etwa in der Mitte und nach hinten eingerollt. Der nach vorn geschlossene Schlitz unmittelbar vor dem Apex, darunter auf der Schaleninnenseite ein Septum (bis $10 \mathrm{~mm}$ lang und bis $7 \mathrm{~mm}$ breit) . . . . . . . Puncturella noachina (Taf. 1, 3 a bis c)

Patellidae

Schale kappen- bis kegelförmig, Umriß \pm elliptisch, ohne Schlitz. Apex zentral oder dem Vorderrande genähert. Schalenaußenseite glatt oder radiär gerippt beziehungsweise gestreift mit \pm deutlichen konzentrischen Zuwachsstreifen. Innen meist glänzend bis irisierend. Haftmuskeleindrücke deutlich.

\section{Patella Linné}

Gehäuse kegelförmig mit kräftigen Radiär--, dazwischen schwächeren Sekundärrippen und deutlichen konzentrischen Anwachsstreifen. Apex etwa in der Mitte. Innenseite glänzend mit einem nach vorn offenen hufeisenförmigen Haftmuskeleindruck. Die beiden freien Enden des Muskeleindrucks sind durch eine Mantellinie verbunden (bis $58 \mathrm{~mm}$ lang) . . . . . . . . . . Patella vulgata (Taf. 2, 1 a bis c)

\section{Helcion Montfort (Ansates Sowerby)}

Gehäuse horngelb, kappenförmig, flacher als die vorige Art, dünnschalig, mit feinen Radiärstreifen, die zum Teil irisierend blau gefärbt sind. Deutliche konzentrische Wachstumsringe. Apex am Vorderrand. Innenseite glänzend, Haftmuskeleindruck mit Mantellinie (bis $20 \mathrm{~mm}$ lang) . . . . . Helcion pellucidus (Taf, 2, 2 a bis c)

\section{Acmaeidae}

Schale napf- oder kappenförmig, den Patellidae ähnlich. Außenseite radiär gestreift, gerippt; glatt. Schaleninnenseite porzellanartig, nicht irisierend.

\section{Acmaea Eschscholtz}

Schale kappenförmig, fein radiär gestreift, konzentrische Anwachsstreifen, meist mit 
dunkelbrauner Fleckenzeichnung. Apex wenig nach vorn verlagert (bis $30 \mathrm{~mm}$ lang) . . . . . . . . . . . . . . Acmaea testudinalis (Taf. 3, 1 a bis c) Schale kappenförmig, schwache Radiär- und Zuwachsstreifen, rötlich gefärbt oder gestrahlt. Apex stark nach vorn gerückt (bis $15 \mathrm{~mm}$ lang) . . . . Acmaea virginea

(Taf. 3,2 a bis c)

\section{Lepetidae}

Gehäuse klein, kappen- oder napfförmig, Schalenaußenseite glatt, fein gerippt oder gekörnelt. Haftmuskeleindruck hufeisenförmig, ähnlich dem der Patellidae.

\section{Lepeta Gray}

Gehäuse kappenförmig, außen radiär gerippt. Apex fast in der Mitte (bis $18 \mathrm{~mm}$ lang) Lepeta caeca (Taf. 3, 3 a, b)

\section{Pilidium FORBES}

Schale kappenförmig, fein radiär gerippt mit wenigen deutlichen konzentrischen Ringen. Apex dem Vorderrand genähert (bis $9 \mathrm{~mm}$ lang) Pilidium fulvum (Taf. 3, $4 \mathrm{a}, \mathrm{b}$ )

\section{Propilidium Forbes \& HANLEX}

Gehäuse kappenförmig, klein, außen Gitterskulptur. Apex fast zentral mit wenig eingerolltem Embryonalgewinde. Innen ein kleines Septum am Wirbel (bis $4 \mathrm{~mm}$ lang) Propilidium ancyloides (Taf. 3, 5 a bis c)

\section{Trochidae}

Schale kegel- bis kreiselförmig, Basis \pm abgeflacht, innen und außen perlmuttrig. Genabelt, häufig durch einen Spindelkallus verdeckt, der mitunter, eingesenkt, einen falschen Nabel bildet. Mündung rundlich oder viereckig, Mündungsinnenrand meist nicht zusammenhängend.

\section{Margarites (LEACH) GRAY}

Schale flach spiralig, dünnwandig, durchscheinend, schwach skulptiert. Gewinde niedrig, Endwindung groß mit gerundeter Mündung. Parietalrand deutlich (bis $9 \mathrm{~mm}$ hoch und bis $11 \mathrm{~mm}$ breit) . . . . . . . Margarites belicinus (Taf, $4,1 \mathrm{a}, \mathrm{b}$ )

\section{Gibbula Risso}

Gehäuse kegelförmig mit schwach gewölbten Umgängen und flacher Basis. Die Naht ist wenig eingesenkt. Schalenwand fest, außen mit Spiralskulptur und stumpfem Apex. Mündung eckig, Nabel durch den Spindelrand wenig eingeengt (bis $20 \mathrm{~mm}$ hoch)

Gibbula cineraria (Taf. 4, 2 a bis c) Schale kreiselförmig mit gewölbteren Umgängen und tiefer Naht sowie spitzem Apex. Skulptur wie vorige Art, rötliche Querstreifen, Nabel durch eine Schwiele verengt (bis $14 \mathrm{~mm}$ hoch). . . . . . . . . . Gibbula tumida (Taf. 4, 3 a bis c) 


\section{Calliostoma SwaInson (Zizipbinus GraY)}

Gehäuse kreiselförmig, oben spitz, an der Basis abgeflacht. Kräftige und feinere Spiralleisten, die, von schrägstehenden Axialrippen gekreuzt, eine granulierte Gitterskulptur ergeben. Rötliches Fleckenmuster. Ungenabelt, Mündung viereckig (bis $18 \mathrm{~mm}$ hoch) .. . . . . . . . . . . . Calliostoma miliare (Taf. 4, 4 a, b) Gehäuse kreiselförmig, oben spitz, an der Basis abgeflacht. Spiralleisten, jedoch ohne Gitterskulptur, gelbe und rote Fleckenzeichnung (bis $18 \mathrm{~mm}$ hoch)

Calliostoma conuloide ( $\mathrm{Taf}, 4,5$ )

\section{Phasianellidae \\ Tricolia Risso}

Schale turbospiral mit stark gewölbten Umgängen, fast glatt, Naht eingesenkt. Bunt gezeichnet mit Tupfen oder marmorierten Linien. Innen keine Perlmutterschicht. Letzte Windung groß. Rundlicher Mundsaum, an der Nahtecke spitzwinklig. Der Spindelrand, der bogig in den Basalrand übergeht, am Parietalrand angedruidkt. Ungenabelt (bis $10 \mathrm{~mm}$ hoch) . . . . . . . . Tricolia pulla (Taf. 5, $1 \mathrm{a}, \mathrm{b}$ )

\section{Neritidae \\ Theodoxus MONTFORT}

Gehäuse breiter als hoch mit flachem Gewinde. Innere Scheidewände resorbiert. Mit Periostrakum und verschiedener dunkler Netz- oder Fleckenzeichnung auf hellem Grund. Innen porzellanartig. Mündung halbkreisförmig, Spindelrand stark verbreitert, abgeflacht und glatt. Ungenabelt (bis $10 \mathrm{~mm}$ lang). . . Theodoxus fuviatilis

(Taf. 5,2 a bis c)

\section{MESOGASTROPODA}

Viviparidae

Gehäuse turbospiral, mäßig hohes Gewinde, Umgänge gewölbt mit deutlicher Naht. Mündung rundlich, an der Nahtecke gewinkelt. Meist schwach skulptiert. Mundrand zusammenhängend. Weiter-, eng- oder ungenabelt.

\section{Viviparus MonTFort (Paludina LAMARck)}

Gehäuse mit spitzem Apex, weiter genabelt (bis $40 \mathrm{~mm}$ hoch) . Viviparus contectus

Gehäuse mit etwas stumpferem Apex, enggenabelt (bis $32 \mathrm{~mm}$ hoch) .................. Viviparus viviparus (Taf. 5, 4 a, b)

\section{Valvatidae}

Gehäuse plan- bis wenig turbospiral, dünnschalig. Umgänge zum Teil mit schiefen Anwachsstreifen. Genabelt. Mündung rund, Mundrand zusammenhängend. 


\section{Valvata O. F. MüLLER}

Schale fast in einer Ebene, planspiral. Weit genabelt, alle Umgänge auf der Basis sichtbar (bis $1,2 \mathrm{~mm}$ hoch) Valvata cristata (Taf. 6, 1 a bis c) Schale mit wenig erhobenem Gewinde, Nabel weit (bis $4 \mathrm{~mm}$ hod) . . . . . . . . . . . . Valvata macrostoma (Taf. 6, 2 a bis c) Schale mit einem Gewinde, fast ebenso hoch wie die Breite des letzten Umganges, Nabel deutlich (bis $6 \mathrm{~mm}$ hoch) . . . . . . Valvata piscinalis (Taf, 6, 3 a, b)

\section{Tornidae \\ Adeorbis S. V. WoOD}

Gehäuse klein, weiß, fast planspiral, mit wenig erhobenem Gewinde. Stark skulptiert, axiale Rippen, Umgänge kantig. Weit genabelt. Mündung weit, Außenrand scharf, Parietalschwiele und Spindelrand deutlich (bis $1 \mathrm{~mm}$ breit)

$$
\text { Adeorbis subcarinatus (Taf. 6, } 4 \text { a, b) }
$$

\section{Rissoidae}

Schale meist klein, turbospiral mit erhobenem Gewinde. Umgänge gewölbt, spiral oder axial skulptiert. Mündung rund, Mundrand zusammenhängend, bisweilen an der Nahtecke geknickt. Außenrand \pm verdickt. Schwach-oder ungenabelt.

\section{Rissoa (Freminville) Desmarest}

Schale schlanker, Gewinde höher als Gehäusebreite. Umgänge \pm gewölbt. Die axialen Rippen lassen den unteren Teil der Endwindung frei, sehr variabel. Außenrand verdickt (bis $4 \mathrm{~mm}$ hoch) . . . . . . . . . . . . Rissoa parva (Taf. 6, 5 a, b) Schale gedrungener, Gewinde etwa Gehäusebreite. Umgänge gewölbt. Skulptur sehr verschieden, mitunter nur letzte Windung mit Rippen, oder ganz fehlend, häufig mit braunen, axialen Farbstreifen. Außenrand \pm verdickt (bis $4,5 \mathrm{~mm}$ hoch)

. . . . . . . . . . . . . . . Rissoa inconspicua (Taf. 6, 6 a, b) Schale spitz kegelförmig, Umgänge flach. Schwach gerippt mit spiralen Grübchenreihen. Mündung außen mit weißem Wulst (bis $5 \mathrm{~mm}$ hoch)

. . . . . . . . . . . . . . . Rissoa violacea (Taf. 7, 1 a, b) Schale dünnwandig mit sehr hohem Gewinde. Umgänge wenig gewölbt, glatt bis gerippt, gelblich bis braun axial gestreift. Sehr variabel. Mündung eiförmig, Mundrand oben nicht so scharf geknickt, sondern leicht gewinkelt. Parietal- und Spindelrand deutlicher als bei vorigen Arten. Mündung leicht ohrförmig erweitert (bis $10 \mathrm{~mm}$ hoch)

$$
\text { Rissoa membranacea (Taf. 7, } 4 \text { a, b) }
$$

\section{Alvania Risso}

Gehäuse mit mäßig hohem Gewinde, Umgänge gewölbt. Kräftige Rippen und etwas dichter stehende Leisten ergeben eine Gitterskulptur mit kleinen, rechteckigen Vertiefungen. Auf der Endwindung von der Nahtecke aus nach unten nur noch spirale Leisten. Mundrand kräftig und oben gewinkelt (bis $6 \mathrm{~mm}$ hoch) Alvania lactea (Taf. 7, 2 a, b) 


\section{Manzonia Brusina}

Schale mit stark gewölbten Umgängen. Kräftige axiale, etwas geschwungene Rippen. Durch feine, auch über die Rippen laufende spirale Leisten entsteht eine Gitterskulptur. Die Endwindung schließt unten mit einem kräftigen Spiralreif die Rippen ab. Mündung rund. Mundrand zusammenhängend, verdickt, mit einem Ringwulst (bis $3 \mathrm{~mm}$ hoch) . . . . . . . . . . Manzonia costata (Taf. 7, 3 a, b)

\section{Cingula Fleming}

Schale dünnwandig, Gewinde hoch, Umgänge gewölbt, Naht tief. Feine Spiralstreifen, mitunter auf den älteren Windungen axiale, etwas schiefe Rippen. Mündung oben spitz gewinkelt. Spindelrand schwach verdickt (bis $3 \mathrm{~mm}$ hoch)

Cingula (Onoba) striata (Taf. 7, 5 a, b) Schale der vorigen Art ähnlich, jedoch glatt, Mündung oben leicht gewinkelt, Spindelrand kaum verdickt (bis $3 \mathrm{~mm}$ hoch) . . . Cingula (Hyala) vitrea (Taf. 7,6 a, b)

\section{Barleeia W. Clark}

Schale spitz kegelförmig mit mäßig gewölbten Umgängen, glatt. Mündung eiförmig, Mundrand zusammenhängend, unten schwach gebuchtet (bis $3 \mathrm{~mm}$ hoch)

- Barleeia rubra (Taf. 8, 2 a, b)

\section{Caecidae \\ Caecum Fleming}

Schale klein, röhrenförmig, leicht gebogen. Anfangsgewinde abgestoßen (Abb. 3), Außen glatt, Mündung kreisrund (bis 2,5 mm lang) . . Caecum glabrum (Taf. 8, 1)

\section{Hydrobiidae}

Gehäuse klein, meist dünnschalig, turbospiral (ähnlich den Rissoidae). Meist glatt, selten skulptiert. Mit dünnem Periostrakum. Mündung rund bis eiförmig; \pm genabelt.

\section{Hydrobia Hartmann}

Schale mit schwach gewölbten Umgängen. Mundrand oben spitz gewinkelt. Eng genabelt (bis $6 \mathrm{~mm}$ hoch). . . . . . . . . Hydrobia ulvae (Taf. 8, 3 a, b) Schale mit stark gewölbten Umgängen. Mundrand oben spitz gewinkelt. Etwas offener genabelt (bis 4,5 mm hoch) . . . . Hydrobia stagnalis (Taf. 8, 4 a, b)

\section{Potamopyrgus Stimpson}

Schale mit mäßig gewölbten Umgängen, die mitunter durch eine spirale Kante \pm gekielt sein können. Mundrand zusammenhängend, oben geknickt. Ungenabelt (bis $6 \mathrm{~mm}$ hoch). . . . . . . . Potamopyrgus jenkinsi (Taf. 8, 5 a bis c)

\section{Bithynia GRAY}

Gehäuse gedrungener und breiter als bei den vorigen Hydrobiiden. Mit schwach gewölbten Umgängen, Mundrand oben geknickt (bis $15 \mathrm{~mm}$ hoch) 
Mit stark gewölbten Umgängen, Mundrand oben nicht geknickt (bis $6 \mathrm{~mm}$ hoch) Bitbynia leachi (Taf. 9, 1 a, b)

\section{Skeneopsidae \\ Skeneopsis IREDALE}

Schale sehr klein mit niedrigem Gewinde. Umgänge außen glatt, Mündung rund, weit genabelt (bis 1,5 $\mathrm{mm}$ hoch) . . . . . . Skeneopsis planorbis (Taf. 9, 2 a bis c)

\section{Omalogyridae \\ Omalogyra JEFFreys (Homalogyra JefFreys)}

Gehäuse sehr klein, planspiral, Umgänge außen glatt, Mündung kreisrund (bis $1,5 \mathrm{~mm} \varnothing$ ) . . . . . . . . . Omalogyra atomus (Taf. 9, 3 a bis c)

\section{Assimineidae \\ Assiminea FLEMING}

Gehäuse klein, turbospiral mit schwach gewölbten Umgängen, axial gestreif, gelblich, zuweilen rot gebändert. Endwindung etwas kantig. Mündung rundlich, an der Nahtecke gewinkelt. Mundränder durch Parietalschwiele verbunden. Ungenabelt (bis $7 \mathrm{~mm}$ hoch) . . . . . . . . . . Assiminea grayana (Taf. 9, 4 a, b)

\section{Lacunidae}

Schale klein, dünnwandig, flaches oder hohes Gewinde. Umgänge glatt oder fein gestreift. Mündung rundlich, genabelt.

\section{Lacuna Turton}

Schale mit höherem Gewinde, Umgänge mit oder ohne bräunliche Spiralbinden. Mündung eiförmig. Nabel offen (bis $14 \mathrm{~mm}$ hoch)

. . . . . . . . . . . . . Lacuna (Epheria) divaricata (Taf. 9, 5 a, b) Schale mit flachem Gewinde. Mündung rundlich, ohrförmig. Nabel weiter als bei der vorigen Art ( $q$ bis 10, $\delta$ bis $4 \mathrm{~mm}$ hoch) . . . . Lacuna pallidula (Taf. 9, 6 a, b)

\section{Littorinidae}

Gehäuse meist dickschalig mit \pm hohem Gewinde, letzter Umgang groß. Glatt oder skulptiert, Mündung rundlich, ungenabelt.

\section{Littorina FERUSSAC}

Schale fast kugelförmig mit flachem Gewinde und stumpfem Apex. Feine Spiral- und deutliche Anwachsstreifen. Farbe variabel, hell bis dunkelbraun (bis $13 \mathrm{~mm}$ hoch) 
Schale \pm spitz kegelförmig mit mäßig hohem Gewinde und spitzem Apex.

(a) mit gewölbten Umgängen, schwachem Parietalrand und etwa senkrecht auf die Endwindung treffendem Palatalrand. Spiralskulptur deutlich, unregelmäßige Anwachsstreifen, Farbe variabel (bis $11 \mathrm{~mm}$ hoch) . . . Littorina saxatilis (Taf. 10, 2 a, b) (b) mit schwach gewölbten Umgängen, deutlichem Parietalrand und bis zum Ansatz nach oben schwenkendem Palatalrand. Keine Spiralskulptur, deutliche Zuwachsstreifen. Farbe: blaugrau (bis $6 \mathrm{~mm}$ hoch) . . . . Littorina neritoides (Taf. 10, $3 \mathrm{a}, \mathrm{b}$ ) Schale \pm stumpf kegelförmig mit flachen Umgängen. Ansatz des Palatalrandes etwa wie bei voriger Art. Feine Spiral- und Zuwachsstreifen. Mitunter axiale und spirale dunkle Bänder (bis $20 \mathrm{~mm}$ hoch) . . . . . Littorina littorea (Taf. 10,4 a bis c)

\section{Turritellidae \\ Turritella LAMARCK}

Gehäuse pfriemenförmig, hoch getürmt bis 19 , oben wenig, nach unten mehr gewölbten Windungen, rötlich-braun gefärbt. Auf jedem Umgang mehrere deutliche Spiralleisten, die von schwächeren Anwachsstreifen gekreuzt werden. Naht deutlich. Mündung von der Nahtecke über den Außen- und Basalrand gerundet bis zum unteren Ende der Spindel. Parietalrand schwielenförmig und fast gerade. Ungenabelt (bis $50 \mathrm{~mm}$ hoch) - Turritella communis (Taf. $11,1 \mathrm{a}, \mathrm{b}$ )

\section{Triphoridae \\ Triphora Blanville}

Schale getürmt wie vorige Art. Umgänge bis zur Endwindung schwach gewölbt. L i n k s g e w u n d e n. Knotige Gitterskulptur. Mündung verhältnismäßig klein, Spindel- und Parietalrand geschwungen. Basalrand wenig eingebuchtet, etwa wie eine Siphonalrinne. Außenrand der Mündung wellig (bis $8 \mathrm{~mm}$ hoch)

- Triphora perversa (Taf. 11, 2 a, b)

\section{Cerithiidae \\ Bittium LEACH (GRAY)}

Gehäuse getürmt mit gewölbten Umgängen. Typische Gitterskulptur. Rechtsgewunden. Mündung rundlich, am Basalrand schwach eingebuchtet, Außenrand nach den auslaufenden spiraligen Leisten wellig (bis $12 \mathrm{~mm}$ hoch) Bittium reticulatum (Taf. $11,3 \mathrm{a}, \mathrm{b}$ )

\section{Scalidae}

Schale meist hoch turbospiral, Umgänge mit \pm kräftigen Rippen. Mündung rund, Mundränder verstärkt, genabelt oder ungenabelt.

\section{Scala Bruguière (Clatbrus OKen)}

Gehäuse mit hohem Gewinde und gewölbten Umgängen, die sich nicht ganz berühren. Krätige axiale, etwas zurückgebogene Rippen, auf den Umgängen einander entspre- 
chend. Zwischenräume glatt, Mündung rundeiförmig, Mundrand zusammenhängend, kräftig, oben mit einem kurzen, auf einer Rippe ruhenden Fortsatz. Ungenabelt (bis $40 \mathrm{~mm}$ hoch) . . . . . . . . . . . . Scala clatbrus (Taf. 11, 4 a, b) Schale mit hohem Gewinde und mäßig gewölbten Umgängen, die sich einander berühren, Naht tief. Rippen flacher und etwas zahlreicher, in den Zwischenräumen feine Spiralstreifen. Mundrand etwa wie vorige Art, jedoch o h n e Fortsatz. Ungenabelt (bis $40 \mathrm{~mm}$ hoch) . . . . . . . . . . . . Scala turtonis (Taf. 11, 5 a, b) Schale klein, mit hohem Gewinde. Umgänge gewölbt, einander berührend, mit zahlreichen dünnen axialen Rippen. Mündung rundeiförmig, Mundrand ziemlich dünn. Ungenabelt (bis $18 \mathrm{~mm}$ hoch) . . . . . Scala clatbratula (Taf. 12, $1 \mathrm{a}, \mathrm{b}$ )

\section{Melanellidae}

Eulima Risso (Melanella Bowdich)

Gehäuse pfriemenförmig mit sehr flachen, glatten und glänzenden Umgängen. Naht nicht deutlich. Endwindung hoch. Mündung an der Nahtecke spitz, unten gerundet, Spindelrand deutlich. Ungenabelt (bis $15 \mathrm{~mm}$ hoch) . . Eulima alba (Taf. 12, 2 a, b)

\section{Stiliferidae}

\section{Pelseneeria Köhler \& VANey (Rosenia Schepman)}

Gehäuse klein, dünnschalig, mit deutlich abgesetztem, griffelförmigem Apex. Endwindung groß und stark gewölbt. Mündung rund, Außenrand scharf, Parietalrand weit. Ungenabelt (bis $4 \mathrm{~mm}$ hoch, $2 \mathrm{~mm}$ breit) . . . . Pelseneeria stylifera (Taf. 12, 3)

\section{Pyramidellidae}

Schale klein, turbospiral, mit \pm hohem Gewinde, Embryonalgewinde gegen die Achse geneigt. Umgänge \pm gewölbt, glatt oder axial gerippt. Mündung gerundet, eiförmig bis etwa viereckig. Spindelrand häufig mit zahnartiger Falte.

\section{Brachystomia MonTERosato}

Gehäuse klein, dünnschalig, wenig erhobenes Gewinde. Umgänge mäßig gewölbt, glatt, Naht tief. Embryonalgewinde flach. Mündung eiförmig, oben gewinkelt. Mundrand nicht zusammenhängend. Spindelrand oben mit einer \pm deutlichen zahnartigen Falte. Enggenabelt (bis $4 \mathrm{~mm}$ hoch) . . . . Brachystomia rissoides (Taf. 12, 4 a, b)

\section{Parthenina Bucquoy, Dautzenberg \& Dollfus}

Gehäuse klein, Gewinde hoch, Umgänge schwach gewölbt mit schmalen, gerade oder etwas gebogenen axialen Rippen, in den Zwischenräumen feine Spiralstreifen. Embryonalgewinde klein, schief. Endwindung unten \pm kantig, mit zuweilen undeutlicher Axialskulptur. Mündung eiförmig, oben gewinkelt, nicht zusammenhängend. Spindelrand oben mit einer zahnartigen Falte. Kaum genabelt (bis $5 \mathrm{~mm}$ hoch) 


\section{Partulida Schaufuss}

Schale sehr klein, breit-kegelförmig mit flach gewölbten Umgängen. Naht tief. Axiale Rippen, die auf der unten kantigen Endwindung durch Spiralleisten abgeschnitten werden. Mündung fast rhombisch, nicht zusammenhängend, an der Nahtecke gewinkelt. Spindelrand oben mit stumpfem Zahn. Ungenabelt (bis $3 \mathrm{~mm}$ hoch)

Partulida spiralis (Taf. 12, 6 a, b)

\section{Turbonilla Risso}

Gehäuse klein, pfriemenförmig, mit hohem Gewinde. Umgänge wenig gewölbt, axial gerippt. Mündung rundlich-viereckig. Mundrand nicht zusammenhängend, Außenrand dünn, Spindelrand ohne zahnartige Falte.

Schale mit etwas schräg gestellten Axialrippen, die auf der unten glatten Endwindung allmählich erlöschen (bis $10 \mathrm{~mm}$ hoch) . . . . Turbonilla lactea (Taf. 13, $1 \mathrm{a}, \mathrm{b}$ ) Schale mit kräftigen, geraden axialen Rippen und spiralen Leisten in ungleichen Abständen. Endwindung unten mit deutlichen Spiralstreifen, auf denen die Rippen erlöschen (bis $11 \mathrm{~mm}$ hoch) . . . . . . . . Turbonilla rufa (Taf. 13, 2 a, b)

\section{Eulimella (Forbes) Gray}

Gehäuse hoch turbospiral mit kaum gewölbten, glatten Umgängen. Mündung rundlich bis viereckig, Mundrand nicht zusammenhängend. Spindelrand ohne Zahn. Embryonalgewinde zur Gehäuseachse schief (bis $5 \mathrm{~mm}$ hoch) Eulimella commutata (Taf. 13, 3 a, b) Anmerkung: Die etwa gleich große, in der Kieler Bucht vorkommende Eulimella (Ebala) nitidissima MonTAGu (nicht abgebildet) ist von der vorigen Art durch folgende Merkmale gut zu unterscheiden: Umgänge gewölbt, mit sehr feinen Spiralstreifen. Mündung eiförmig (bis $4 \mathrm{~mm}$ hoch).

\section{Naticidae}

Gehäuse kugelig mit wenig erhobenem Gewinde. Umgänge glatt oder fein axial gestreift. Mündung rundlich bis halbkreisförmig, \pm genabelt. Spindelrand mitunter schwielig und über dem Nabel verbreitert.

\section{Lunatia GRAY}

Schale mit \pm gewölbten Erstwindungen. Mündung halbkreisförmig. Spindel- und Parietalrand schwielig.

Gehäuse mit gewölbten Erstwindungen. Umgänge gelblich, ohne Fleckenzeichnung. Nabel von einer Schwiele des Spindelrandes etwas verdeckt (bis $10 \mathrm{~mm}$ hoch) . . . . . . . . . . . . . Lunatia montagui (Taf. 13, 4 a, b) Gehäuse mit schwach gewölbten Erstwindungen. Umgänge elfenbeinfarben, glänzend, mit braun-roten länglichen, gewinkelten bis runden Flecken, die häufig in Spiralreihen angeordnet sind. Nabel offen (bis $18 \mathrm{~mm}$ hoch) . . Lunatia nitida (Taf. 13, $5 \mathrm{a}, \mathrm{b}$ ) Gehäuse mit gewölbten Erstwindungen. Umgänge gelblich mit schrägstehenden braunen bis rötlichen \pm länglichen Flecken unter der Naht, besonders auf der Endwindung (bis $30 \mathrm{~mm}$ hoch) . . . . . . . . . . Lunatia catena (Taf. 14, $1 \mathrm{a}, \mathrm{b}$ ) 


\section{Amauropsis Mörch}

Schale mit mäßig erhobenem Gewinde. Umgänge etwas abgesetzt, gewölbr mit feinen Axialstreifen. Mündung groß, eiförmig. Mundränder zusammenhängend, oben gewinkelt. Spindelrand bedeckt die Nabelgegend (bis $40 \mathrm{~mm}$ hoch)

$$
\text { Amauropsis islandica (Taf. 14, } 2 \text { a, b) }
$$

\section{Lamellariidae}

Schale dünn mit kleinem Gewinde. Umgänge mit Periostrakum, 士 skulptiert. Mündung groß, rundlich, Außenrand scharf, an der Nahtecke gewinkelt, Innenrand schmal und ohne Skulptur. Ungenabelt.

\section{Lamellaria Montagu}

Schale durchscheinend, mit dünnem Periostrakum. Erstwindungen niedrig. Mündung sehr groß, schief eiförmig, Außenrand dünn. Spindelrand umgeschlagen, schmal. Ungenabelt (bis $18 \mathrm{~mm}$ breit) . . . . . . . Lamellaria perspicua (Taf. 14, 3)

\section{Velutina Fleming}

Schale wenig kräftiger, mit dickerem, braunem, spiral, zum Teil axial gestreiftem Periostrakum. Mündung rundlich. Spindelrand nur wenig umgeschlagen. Ungenabelt (bis $26 \mathrm{~mm}$ breit) . . . . . . . . . Velutina velutina (Taf. 15, $1 \mathrm{a}, \mathrm{b}$ )

\section{Cypraeidae \\ Trivia GraY}

Gehäuse klein, involut gewunden. Eiförmig mit Mündungsschlitz in Richtung der Achse. Gewinde verdeckt. Starke spirale Leisten, am Außenrand aufgewellt (bis $13 \mathrm{~mm}$ hoch) . . . . . . . . . . . . Trivia monacha (Taf. 15, 2 a, b)

\section{Calyptraeidae \\ Crepidula LAMARCK}

Schale mittel bis groß, \pm flach. Gewinde sehr klein mit wenigen Umgängen, die am Rande der länglich eiförmigen Mündung eine kleine Ausbuchtung der Endwindung ergeben. Den hinteren Teil der Mündung bedeckt zur Hälfte ein Septum. Häufig rötlich-braune Fleckenzeichnung. Schwach radial und axial skulptiert (bis $47 \mathrm{~mm}$ lang) Crepidula fornicata (Taf. 15, 3 a bis c)

\section{Capulidae \\ Capulus Montfort}

Schale mützenförmig mit nach hinten fast planspiral eingerolltem, kleinem Gewinde. Endwindung stark erweitert. Außen ein mit Borsten besetztes Periostrakum, Mündung rund, innen porzellanartig, ohne Septum (bis $40 \mathrm{~mm} \varnothing$ ) 


\section{Aporrhaidae \\ Aporrbais DA CosTA}

Schale mittel bis mäßig groß. Gehäuse der jugendlichen Tiere turbospiral, mit axialen, knotenartigen Rippen, einer länglichen Mündung, deren Außenrand dünn ist und unten siphonalrinnenartig ausläuft. Gehäuse von ausgewachsenen Tieren mit flügelförmig erweitertem Mündungsaußenrand, im oberen Teil der Mündung ein dem Gewinde \pm angehefteten Fortsatz, unten siphonalrinnenförmig verlängert. Spirale Knotenreihen kräftig (bis $50 \mathrm{~mm}$ hoch) . . Aporrbais pespelecani (Taf. 16, 2 a bis c)

\section{NEOGASTROPODA}

Muricidae

Gehäuse meist größer, turbospiral, \pm dickschalig, Umgänge schwach oder kräftig skulptiert, mitunter knotige, schuppige Spiralleisten oder axiale Rippen. Siphonalrinne stets vorhanden. Mündungsaußenrand glatt, scharf, wellig bis stark gefaltet verdickt, innen häufig gezähnt oder gerieft.

\section{Tritonalia FLEMING}

Gehäuse groß, dickwandig. Gewinde $=1 / 2$ Achsenhöhe. Ungänge abgesetzt, kantig, mit kräftigen, blättrigen Rippen und Leisten. Mündung eiförmig, Außenrand verdickt und innen gefaltet. Siphonalrinne mäßig lang, nach links abgebogen, bei Schalen von ausgewachsenen Tieren stets geschlossen (bis $65 \mathrm{~mm}$ hoch)

Tritonalia erinacea (Taf. $17,1 \mathrm{a}, \mathrm{b}$ )

\section{Urosalpinx STIMPSON}

Schale kräftig, mittelgroß. Gewinde = 1/2 Achsenhöhe. Umgänge gewölbt, mit Gitterskulptur durch breite, flache, axiale Rippen und enger stehende scharfe spirale Leisten. Mündung eiförmig, Außenrand kräftig, innen gezähnt. Siphonalrinne mäßig lang, stets offen, nach unten gebogen (bis $30 \mathrm{~mm}$ hoch). . Urosalpinx cinerea (Taf. 17, $2 \mathrm{a}, \mathrm{b}$ )

\section{Trophonopsis Bucquoy, Dautzenberg \& DOllfus}

Gehäuse spindelförmig, Gewindehöhe wie vorige Art. Umgänge gewölbt, axiale oder Gitterskulptur. Mündung eiförmig mit verhältnismäßig langer Siphonalrinne.

Schale gegittert skulptiert, Außenrand der Mündung wellig, innen gezähnelt (bis $18 \mathrm{~mm}$ hoch) . . . . . . . . Trophonopsis muricatus (Taf. 17, 3 a, b) Schale nur mit axialen, scharfen Lamellen. Mündungsaußenrand dünn und glatt (bis $15 \mathrm{~mm}$ hoch) . . . . . . . . Tropbonopsis clatbratus (Taf. 17, 4 a, b)

\section{Nucella (BOLTEN) RöDING}

Gehäuse dickwandig. Umgänge schwach gewölbt, mit deutlichen Spiralreifen und \pm deutlichen axialen Zuwachsstreifen. Mündung schmal. Siphonalrinne kurz, breit offen (bis $40 \mathrm{~mm}$ hoch) . . . . . . . . . . . Nucella lapillus (Taf. 18, $1 \mathrm{a}, \mathrm{b}$ ) 
Buccinidae

Gehäuse mitunter sehr groß. Umgänge \pm gewölbt, fast glatt, fein oder mäßig skulptiert. Mündung unten mit kürzerer oder längerer Siphonalrinne.

\section{Buccinum LINNÉ}

Gehäuse groß, mit hornigem Periostrakum. Umgänge gewölbt, mit breiten, flachen axialen Rippen, die bei dickschaligen Exemplaren durch Zuwachsstreifen mitunter zerklüftet sind und enger stehenden spiralen Reifen. Mündung weit, eiförmig, Siphonalrinne breit und kurz. Außenrand dünn, innen glatt (bis $110 \mathrm{~mm}$ hod)

\section{Buccinum undatum (Taf. 18, 2 a bis c)}

\section{Neptunea (BOLTEN) RöDING}

Schale groß, Gewinde etwa 1/2. Gehäusehöhe. Umgänge stark gewölbt, etwas kantig, axial und spiral fein gestreift. Mündung weit, oben gewinkelt, unten mit langer, breiter, wenig gebogener Siphonalrinne. Außenrand dünn, innen glatt (bis $200 \mathrm{~mm}$ hoch). . . . . . . . . . . . . Neptunea antiqua (Taf. 19, 1 a, b)

\section{Volutopsius Mörch}

Gehäuse kräftig, Gewrinde mäßig hoch. Umgänge gewölbt, axial und spiral schwach gestreift. Mündung weit, unten mit kurzer Siphonalrinne. Außenrand glatt (bis $90 \mathrm{~mm}$ hoch). . . . . . . . . . Volutopsius norvegicus (Taf. 19, 2 a, b)

\section{Sipho (KLEIN) BrUGUIÈre}

Gehäuse spindelförmig, Gewinde hoch. Umgänge wenig gewölbt, spiral gestreif. Mündung verhältnismäßig klein, mit langer Siphonalrinne. Außenrand einfach, innen glatt (bis $70 \mathrm{~mm}$ hoch) . . . . . . . Sipho gracilis (Taf. 20, 1 a, b)

\section{Nassariidae \\ Nassarius FrorieP}

Gehäuse mittelgroß, Gewinde mäßig hoch. Umgänge schwach gewölbt, mit axialen Rippen und spiralen Streifen. Endwindung unten mit einem kurzen Hals, der durch eine tiefe Rinne begrenzt ist. Mündung eiförmig, oben mit rundlicher Ausbuchtung. Außenrand \pm verdickt, Siphonalrinne kurz (bis $35 \mathrm{~mm}$ hoch)

. . . . . . . . . . . . . Nassarius reticulatus (Taf. 20, 2 a, b) Gehäuse klein, ziemlich dickschalig, Gewinde mäßig hoch. Umgänge stark gewölbt, mit gleichmäßigen axialen Rippen und Spiralstreifen. Endwindung unten mit kurzem Hals. Mündung rundlich, Außenrand mit deutlichem Varix, innen gezähnt. Siphonalrinne kurz (bis $15 \mathrm{~mm}$ hoch) . . . . . . Nassarius incrassatus (Taf. 20,3 a, b)

\section{Turridae}

Schale turbospiral, mit axialer und spiraler Skulptur. Umgänge gewölbt oder kantig. Mündung länglich, oben, an der Nahtecke, mit einer \pm tiefen Einbuchtung (Analsinus). Siphonalrinne nur wenig von der Mündung abgesetzt. 


\section{Lora GISTEL}

Schale klein, Gewinde etwa 1/2 Gehäusehöhe. Umgänge kantig, mit kräftigen Axialrippen und feineren Spiralstreifen. Mündung langgezogen, Außenrand dünn und oben schwach eingebuchtet (bis $18 \mathrm{~mm}$ hoch) . . . . Lora turricula (Taf. 20, $5 \mathrm{a}, \mathrm{b}$ )

\section{Mangelia Risso}

Schale klein, schmal. Gewinde ca. 1/2 Gehäusehöhe. Ungänge gewölbt, nur mit Axialrippen und \pm breiten, gelblich bis braun gefärbten Spiralbändern. Mündung schmal, Außenrand verdickt, oben mit Analsinus (bis $10 \mathrm{~mm}$ hoch)

$$
\text { Mangelia costata (Taf. } 20,6 \mathrm{a}, \mathrm{b})
$$

\section{Pbilbertia Monterosato}

Schale klein, Gewinde höher. Umgänge gewölbt. Gitterskulptur durch kräflige axiale Rippen und lamellenartige, dünne Spiralleisten. Mündung langgezogen, Außenrand oben mit flachem Analsinus, innen gezähnelt (bis $10 \mathrm{~mm}$ hoch)

\section{ZUSAMMENFASSUNG}

1. Im Anschluß an eine frühere taxonomische Bearbeitung der Muscheln oder Bivalvia (Ziegelmeier 1957) werden Bestimmungsschlüssel für die Schnecken (Gastropoda Prosobranchia) der deutschen Meeresgebiete und brackigen Küstengewässer vorgelegt.

2. Die Bestimmungsschlïssel basieren auf Schalenmerkmalen. Sie werden durch 20 Tafeln und 7 Abbildungen illustriert.

3. Eine kurze Einführung in die äußere Anatomie der Gastropoda und Erläuterungen technischer Termini sollen auch dem jungen Studenten und interessierten Laien eine Bestimmung ermöglichen.

\section{ZITIERTE LITERATUR}

Für die systematische Einteilung der Schnedken, die Einführung und den Bestimmungsschlüssel ist folgende Literatur benutzt worden, die auch für das eingehendere Studium der in der vorliegenden Darstellung angeführten Arten zu empfehlen ist:

ANkEL, W. E., 1936. Prosobranchia. In: Tierwelt der Nord- und Ostsee. Gegr. von G. Grimpe \& A. E. Wagler. Akad. Verl. Ges., Leipzig 9 b 1, 1-240.

Benthem-Jutting, T. van, 1933. Mollusca (1) A. Gastropoda Prosobranchia et Pulmonata. Fanna Ned. 7, 1-387.

BoetrGer, C. R., 1952. Die Stämme des Tierreichs in ihrer systematischen Gliederung. $A b b$. braunschw. wiss. Ges. 4, 238-300.

Brohmer, P., 1955. Meeresstrand. Quelle \& Meyer, Heidelberg, 162 pp. (Deutschlands Pflanzen- und Tierwelt).

BuCHNER, O., 1913. Einführung in die europäische Meeresmollusken-Fauna. Schr. dt. LebrerVer. Naturk. 29, 1-166. 
Caspers, H., 1938. Die Bodenfauna der Helgoländer Tiefen Rinne. Helgoländer wiss. Meeresunters. 2, 1-112.

DieHL, M., 1956. Die Raubschnecke Velutina velutina als Feind und Bruteinmieter der Ascidie Styela coriacea. Kieler Meeresforsch. 12, 180-185.

Forbes, E. \& Hantey, S., 1853. A history of British mollusca and their shells. Van Voorst, London, Pt 2-4.

Hagmeier, A., 1951. Die Nahrung der Meerestiere. In: Handbuch der Seefischerei Nordeuropas. Hrsg, von H. Lübbert, E. Ehrenbaum \& A. Willer. Schweizerbart, Stuttgart, Bd 1, H. 5 b, 87-242.

Heincke, Fr., 1894. Die Mollusken Helgolands. Wiss. Meeresunters. (Abt. Helgoland) N. F. 1, $121-153$.

JAECKEL, S. H., 1952. Die Muscheln und Schnecken der deutschen Meeresküsten. Geest \& Portig, Leipzig, 67 pp. (Neue Brehm-Bücherei. H. 72.)

- 1953. Praktikum der Weichtierkunde. G. Fischer, Jena, 86 pp.

- 1954. Weichtiere. De Gruyter \& Co., Berlin, 92 pp. (Das Tierreich. 5.- Slg Göschen. Bd 440.)

- 1957. Mollusca - Weichtiere. In: Exkursionsfauna von Deutschland. Hrsg. von E. Stresemann. Volk und Wissen VEV, Berlin, T. Wirbellose. 1, 99-225.

KaEstner, A., 1955. Lehrbuch der speziellen Zoologie. G. Fischer, Stuttgart, T. 1: Wirbellose, 221-483.

Kuckuck, P., 1962. Der Strandwanderer. 9. Aufl. J. F. Lehmann, München, 148 pp.

ThIELE, J, 1931. Handbuch der systematischen Weichtierkunde. G. Fischer, Jena, 1, 1-778.

Wenz, W., 1938-1944. Gastropoda. In: Handbuch der Paläozoologie. Hrsg. von O. H. Schindewolf. Borntraeger, Berlin, Bd 6, T. 1.1-2, 1-1639.

Ziegelmeier, E., 1957. Die Muscheln (Bivalvia) der deutschen Meeresgebiete. Helgoländer wiss. Meeresunters. 6, 1-51.

- 1963. Das Makrobenthos im Ostteil der Deutschen Bucht nach qualitativen und quantitativen Bodengreiferuntersuchungen in der Zeit von 1949-1960. Veröff. Inst. Meeresforsch. Bremerh. 8 (Sonderbd. 3. Meeresbiologisches Symposion), 101-114. 


\section{Tafel 1}

1 Scissurella crispata FLEMING.

(a) Mündungsaufsicht, (b) Schale von der Rückseite, (c) Gehäuse von oben auf Apex und Gewinde gesehen. Norwegische West- und Südküsten, Oslofjord, Bohuslän. Von Ostgrönland, Spitzbergen an den westeuropäischen Atlantikküsten bis Azoren, Mittelmeer.

Vorkommen und Verbreitung in der vorliegenden Darstellung hauptsäcblich nach ANKEL (1936) zusammengestellt.

2 Emarginula fissura LinNÉ (Patella $f$. LinNÉ).
(a) Ansicht von oben, (b) von innen, (c) von der rechten Seite. Doggerbank, englische Ostküsten, Kattegat, Eingang Oresund. Europäische Atlantikküste von den Faröern bis ins Mittelmeer.

3 Puncturella noachina LrNnÉ (Patella n. LINNÉ).
(a) Apexaufsicht, (b) Ansicht von innen, (c) von der linken Seite. Leere Schalen in der Helgoländer Tiefen Rinne. Doggerbank, englische Ostküsten, Kattegat, Bohuslän, norwegische West- und Südküster. Nordatlantische Ostküsten von Island und Spitz- bergen bis in Höhe der Iberischen Halbinsel; Beringsee, Japan. 


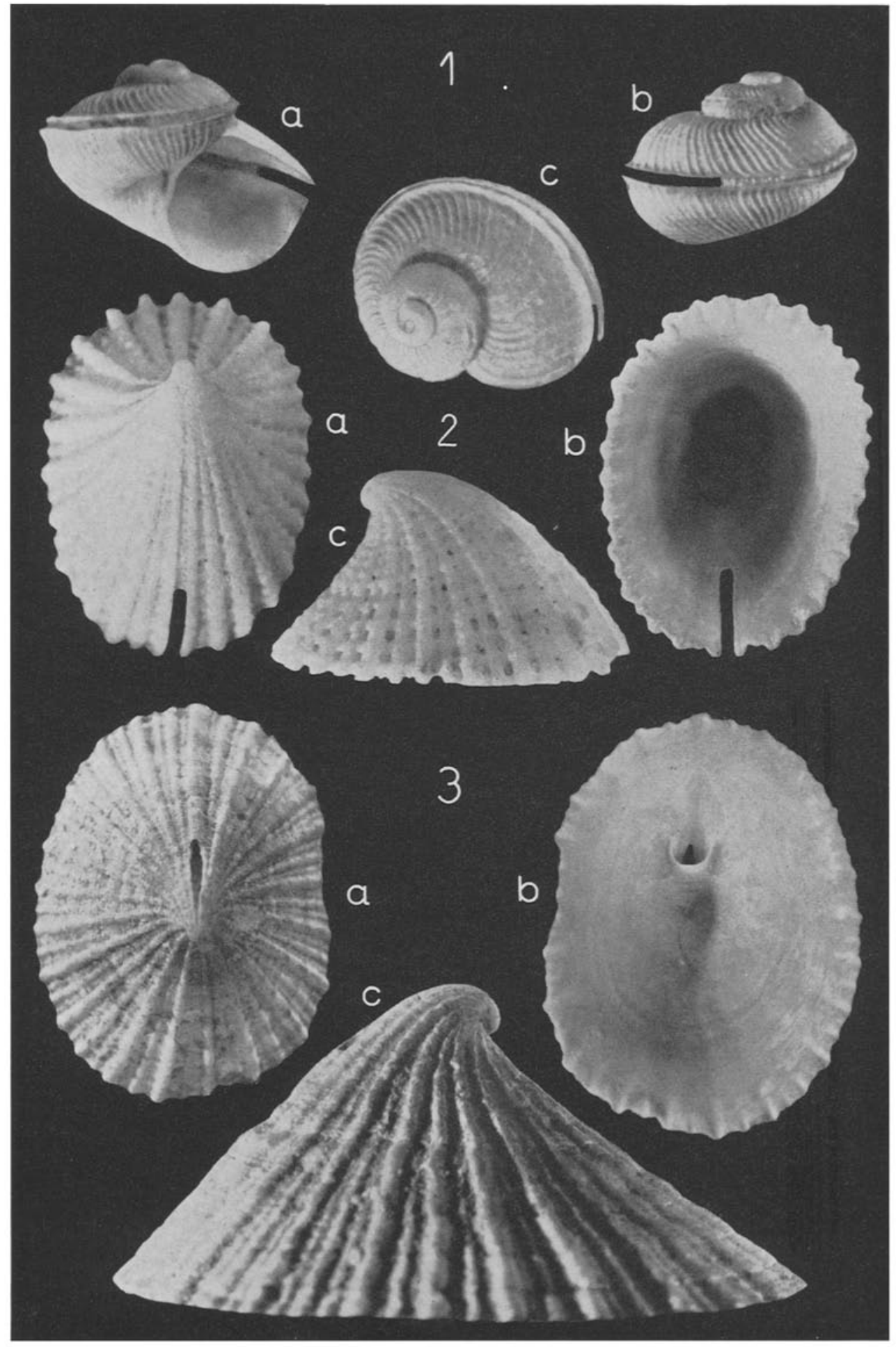

Tafel 1 


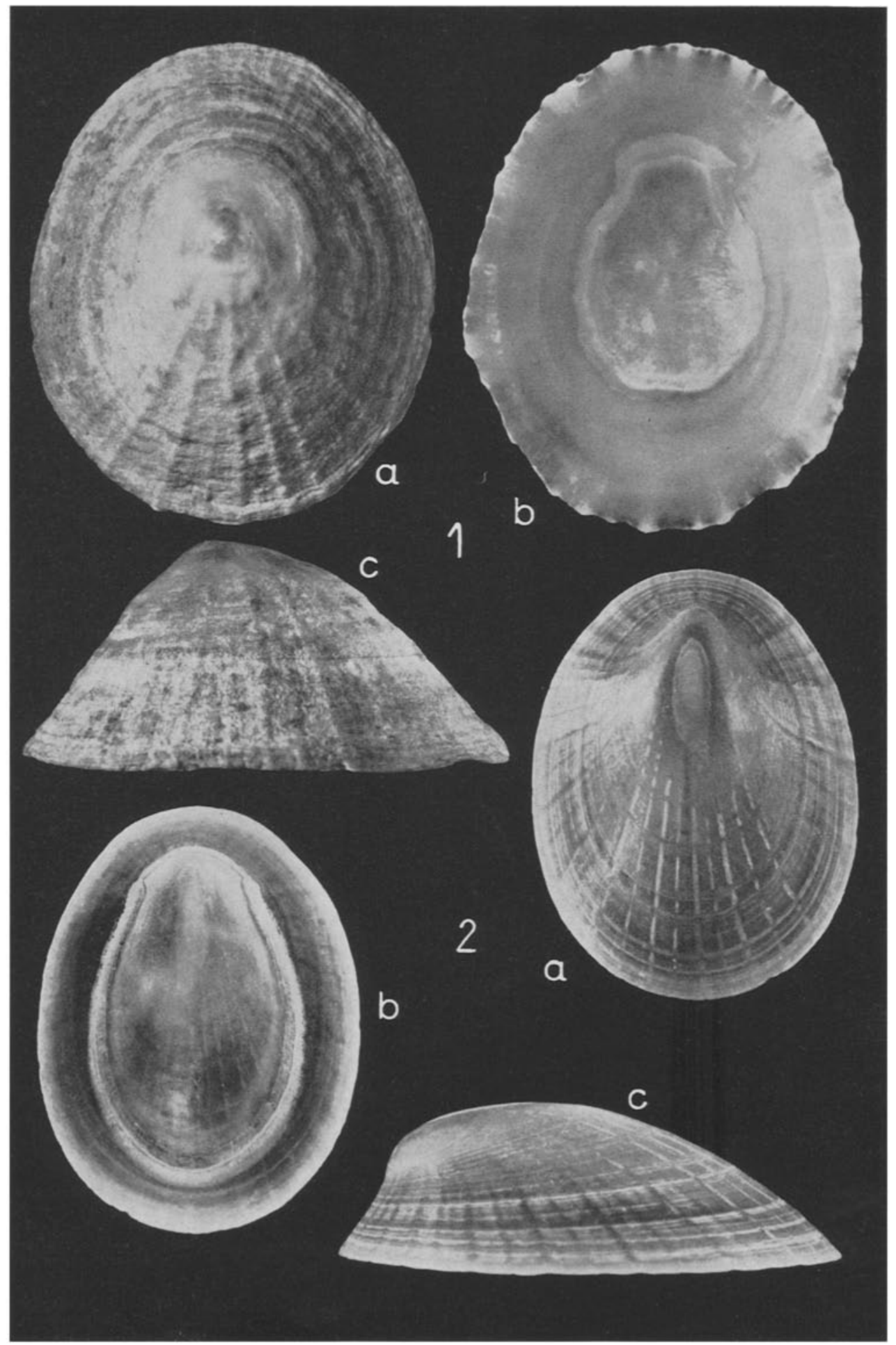

Tafel 2 
Tafel 2

1 Patella vulgata LinNÉ, Gemeine Napfschnecke.

(a) Ansicht auf den Apex, (b) auf die Innenseite, (c) von der linken Seite. Bewohnt felsigen Untergrund in der Gezeitenzone, auch bei stärkstem Wellenschlag. Schalenrand paßt sich den Unebenheiten des Wohnplatzes an. Nicht in der Deutschen Bucht. Bei der hier abgebildeten Schale handelt es sich um ein Exemplar, das auf einem Stein mit Lithothamnion unter Fucus an der Westseite von Helgoland am 20. Februar 1913 lebend gefunden wurde. Englische Ostküste, holländische und belgische Küsten, europäische Atlantikküisten von den Lofoten bis zu den Kapverdischen Inseln, auch Mittelmeer.

2 Helcion pellucidus Linné (Patella pellucida LinnÉ, Patina p. Linné), Durchsichrige Napfschnecke.

(a) Gehäuse von oben, (b) von innen, (c) von der linken Seite gesehen. Bei Helgoland auf Laminaria. Nordeuropäische Meeresgebiete bis zum Mittelmeer. 
Tafel 3

1 Acmaea testudinalis O. F. MüLler, Schildkrötenschnecke.

(a) Schale von oben, (b) von innen, (c) von der linken Seite gesehen. Auf Steinen in der Kieler Förde. Öresund, mittlere und nördliche Nordsee. Nordatlantik, Azoren, von den norwegischen Küsten bis zum Beringsmeer; Japan, Mexiko, Antillen.

2 Acmaea virginea O. F. MüLLER.

(a) Außen-, (b) Innenseite, (c) rechte Seite der Schale. Bei Helgoland auf Steinen mit Lithothamnion, nach HerNCKE (1894) "gemein um die ganze Insel" ${ }^{\text {c }}$. Westliche Nordsee, von den norwegischen Küsten bis zum Öresund. Ostatlantische Küisten von Island bis zu den Kapverdischen Inseln, auch Mittelmeer.

3 Lepeta caeca. O. F. MÜhLER.

(a) Linke Schalenseite, (b) von innen gesehen. Von den norwegischen West- und Südküsten bis zum Orresund. Nordatlantik, nördliche Eismeerküsten bis zu den Azoren.

4 Pilidium fulvum O. F. MÜLLER (Lepeta fulva MÜLLER).

(a) Gehäuse yon oben, (b) rechte Schalenseite. Nach Koвelt aus Heincke (1894)

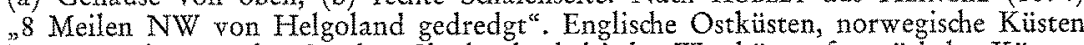
bis zum Eingang des Sundes. Shetlands, britische Westküste, französische Küsten, Azoren.

5 Propilidium ancyloides Forbes.

(a) Apex-Aufsicht, (b) Innenseite, (c) Schale von rechts gesehen. Nördliche Nordsee bis Lofoten, englische Westküsten, Kanaren, Mittelmeer. 


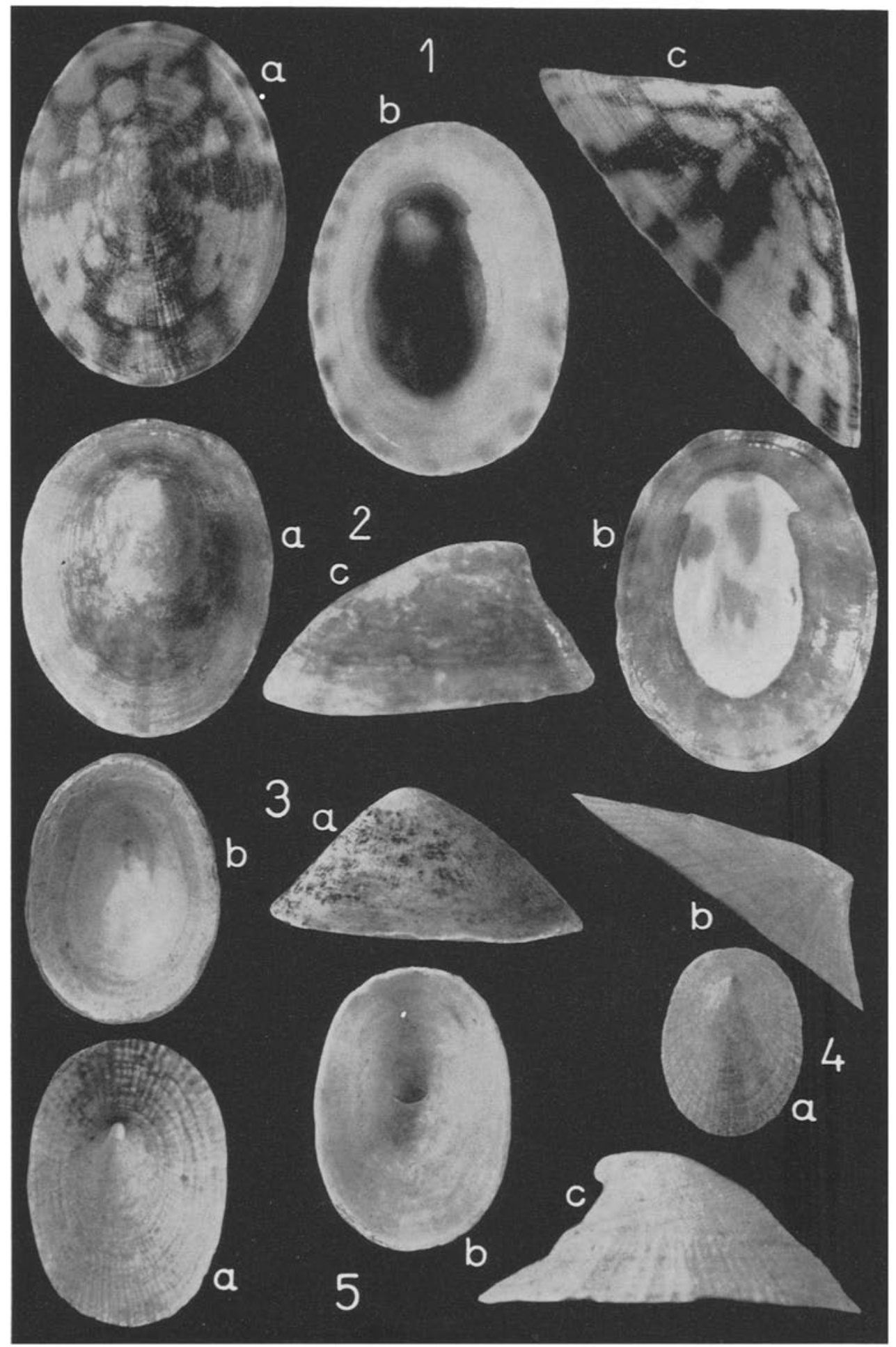

Tafel 3 


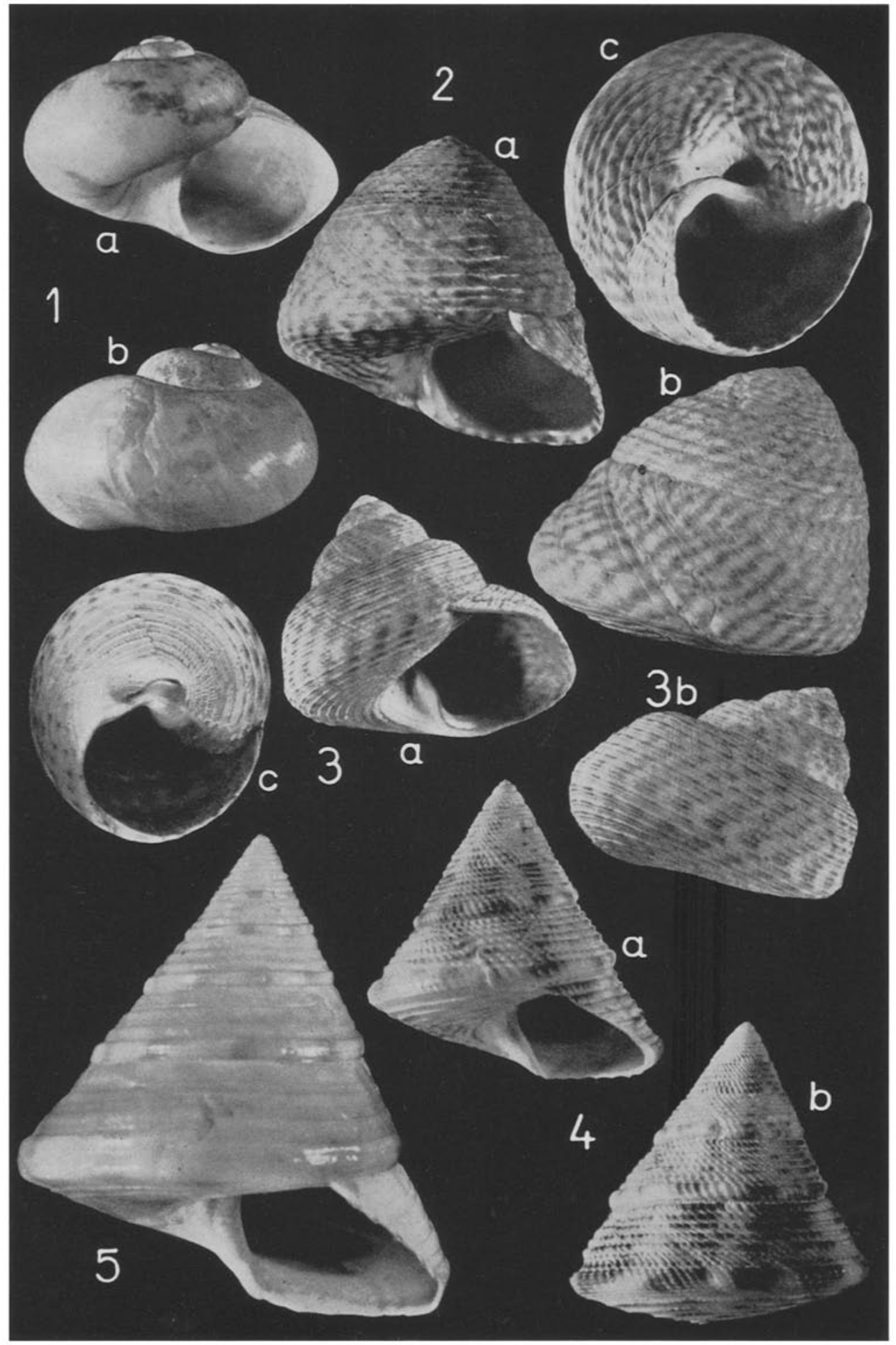

Tafel 4 


\section{Tafel 4}

1 Margarites belicinus Farricius.

(a) Mündungs-, (b) Rückansicht. Nordische Form, nach Ankel (1936) „Nordsee in der Laminarienzone". Arktisch-boreal.

2 Gibbula cineraria LinNé (Trochus c. LINNÉ), Aschfarbige Kreiselschnecke.

(a) Auf die Mündung, (b) die Rückseite, (c) auf die Basis und den Nabel gesehen. Bei Helgoland im Felswatt häufig. Nach Henccke (1894) „eine der gemeinsten Schnecken Helgolands". An den Kï̈sten der mittleren und nördlichen Nordsee, von den West- und Südküsten Norwegens bis zum Oresund. Holländische und belgische Kïsten bis Mittelmeer, auch Schwarzes Meer.

3 Gibbula tumida Montagu (Trochus tumidus Montagu), Spitze Kreiselschnecke.

(a) Mündungs-, (b) Rückseiten-, (c) Basisansicht. Bei Helgoland in tieferem Wasser (Tiefe Rinne) auf steinigem mit Schlick vermischtem Grobsand. Verbreitung etwa wie vorige Art, etwas nördlicher bis Island, nicht Schwarzes Meer.

4 Calliostoma miliare Brocchi (Trochus miligranus Phulıpi).

(a) Mündungsansicht, (b) von der entgegengesetzten Seite. Nördliche Nordsee, norwegische West- und Südküsten bis Oresund, englische Westküsten bis ins Mittelmeer.

5 Calliostoma conuloide LAMARCK (Trochus ziziphinus JEFrReYs), Bunte Kreiselschnecke. Nach Heincke (1894) nördlich Helgoland nicht häufig „auf den pflanzenleeren, grobsandigen und steinigen Gründen" im Sublitoral. Vor 1894 "in großer Menge bei der Hummerfischerei in den Hummerkörben gefunden". Von Norwegen bis Bohuslän, Doggerbank, an den nordatlantischen Küsten yon den Orkneys und Shetlands bis Madeira, Kanaren, auch Mittelmeer. 


\section{Tafel 5}

1 Tricolia pulla LINNÉ (Phasianella p. LINNÉ).

(a) Mündungs-, (b) Rückseite. Von den englischen Küsten bis zu den Kanaren, auch Mittelmeer und Schwarzes Meer. (Die hier abgebildete Schale aus dem Nat. Mus. Senckenberg $=$ Tricolia pulla LinNé var. picta DA CosTA [Kanaren]).

2 Theodoxus fuviatilis LinNÉ (T. Lutetianus MonTfort, Nerita fuviatilis LinNÉ).

(a) Mündungsansicht, (b) und (c) verschieden gefärbte Schalen von der Rückseite. Im Brackwasser der Ostsee (nach ANKEL 1936 bis $16 \%$ S) und holländischen wie dänischen brackigen Gewässern.

3 Viviparus contectus MrLlet (V. viviparus LinnÉ).

(a) Ansicht auf die Mündung, (b) Rückseite. Auch im Brackwasser der Nord- und Ostseeküsten.

4 Viviparus viviparus LiNNé (V. fasciatus O. F. MÜlLeR).

(a) Mündungsansicht, (b) von der Rückseite gesehen. Vorkommen wie vorige Art. 


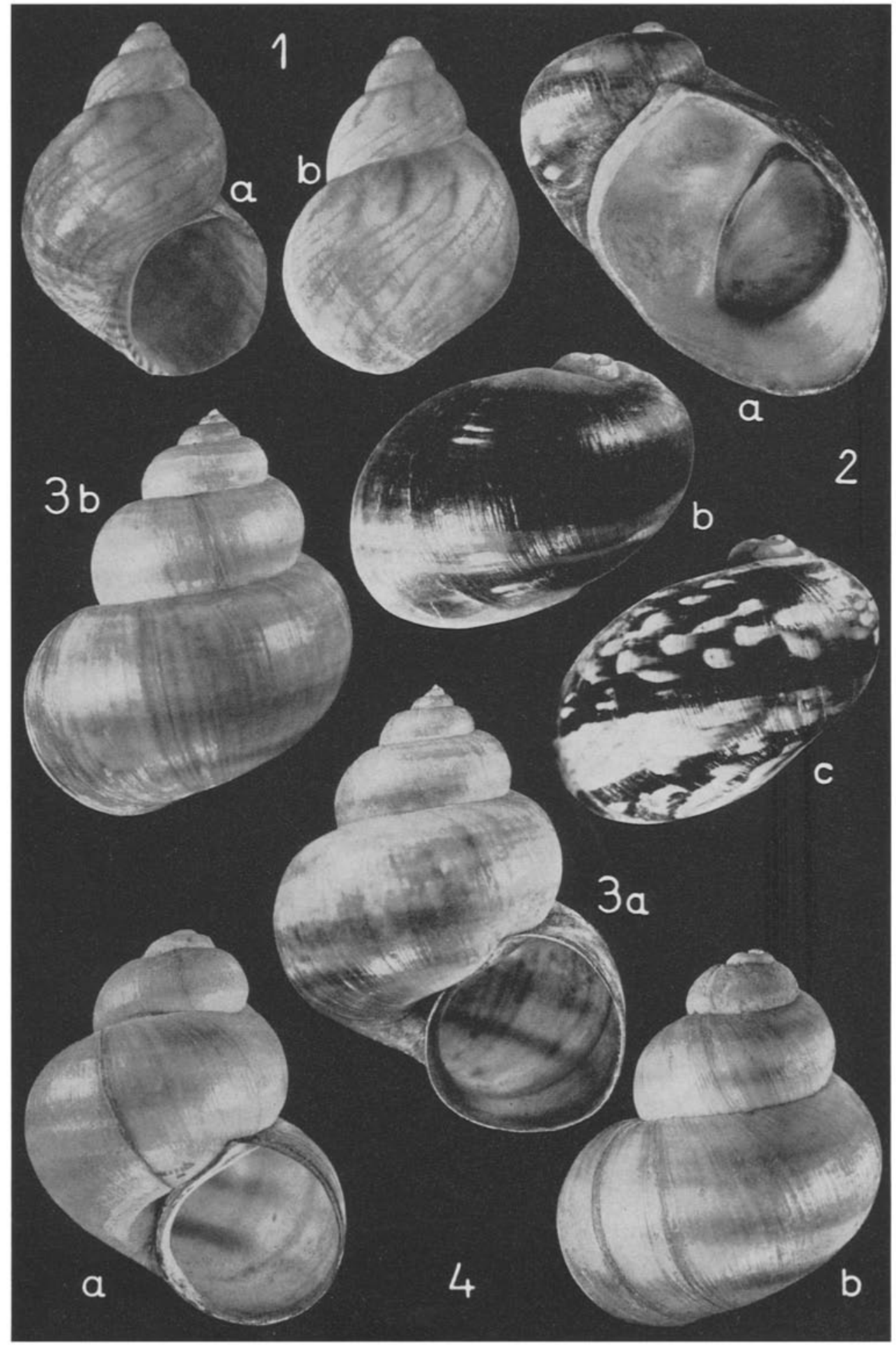




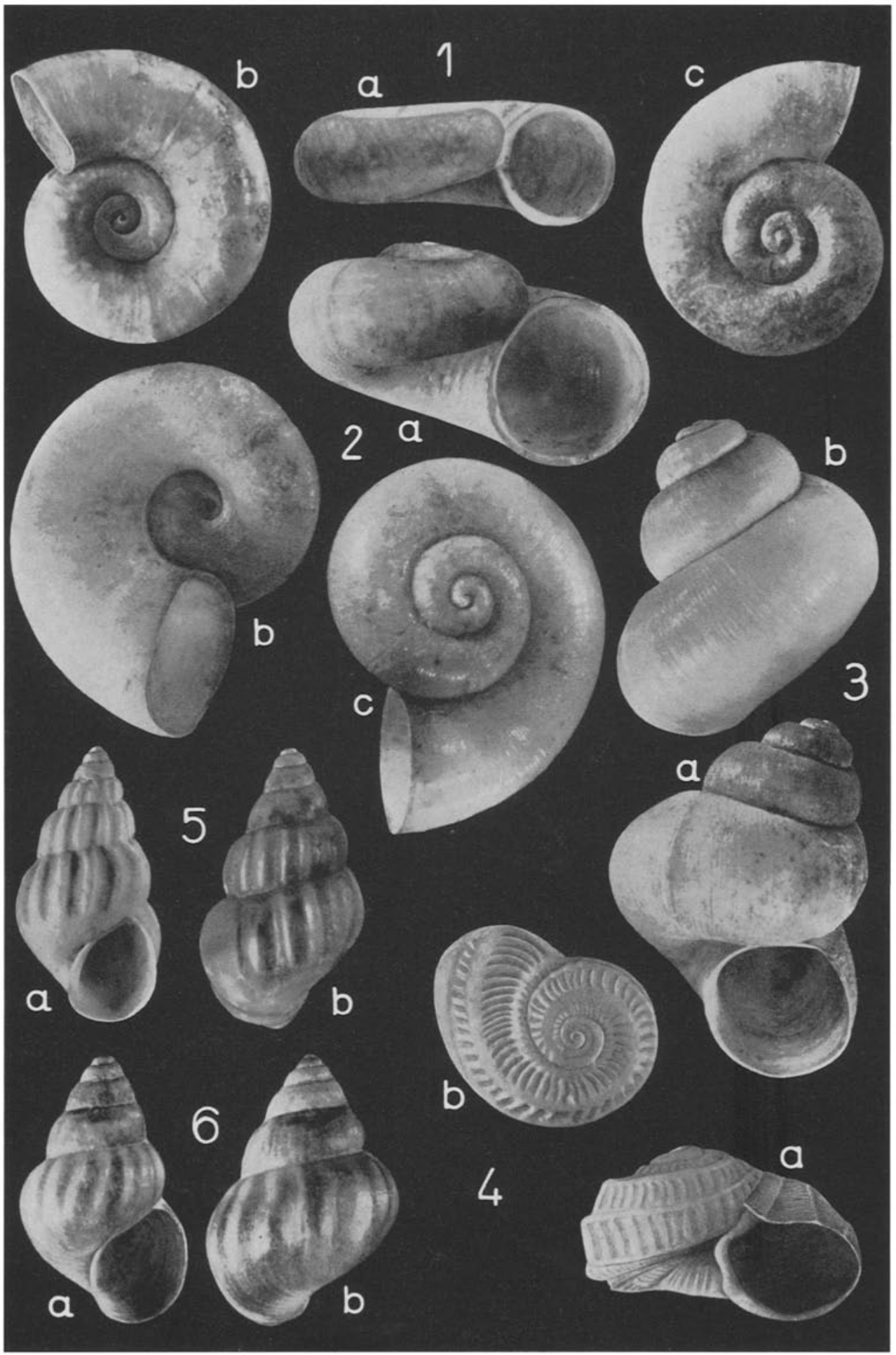

Tafel 6 


\section{Tafel 6}

1 Valvata cristata O. F. Müller.

(a) Mündungsansicht, (b) auf die Basis mit Nabel, (c) auf den Apex gesehen. Brackw asserform.

2 Valvata macrostoma STEEnbuch (V. pulchella Studer).

(a) Mündungsansicht, (b) Nabel-, (c) Apexseite. Gelegentlich im Angespül.

3 Valvata piscinalis O. F. MÜLLER.

(a) Mündungs-, (b) Rückansicht. Brackwasser der Nord- und Ostseeküsten.

4 Adeorbis subcarinatus Montagu (Tomnss. Montagu).

(a) Auf die Mündung, (b) auf den Apex gesehen. Holländische Küste, englische Ostküiste. Britische Westküste, französische Küste, Mittelmeer.

5 Rissoa parva Da Costa (Turboella p. DA Costa).

(a) Mündungs-, (b) Rückansicht. Nadh HeINCKe (1894) „die gemeinste Schnecke Helgolands ${ }^{\text {cc }}$, in großen Mengen zwischen Pflanzen und den Pflanzenrasen der Kreideklippen und in den Spalten des Kalkgesteins. Im Angespül der friesischen Inseln häufig. Nordsee, Ostatlantik von den norwegischen Küsten, Shetlands bis zu den Kanaren.

6 Rissoa inconspicua Alder ( $R$. albella Loven).

(a) Mündungs-, (b) Rückansicht. Nordsee (Helgoland?), westliche Ostsee. 


\section{Tafel 7}

1 Rissoa violacea Desmarest (R. ruflabrum Leach).

(a) Mündungs-, (b) Rückansicht. Nordsee (Helgoland?), Kieler Bucht. Ostatlantikküsten bis Mittelmeer.

2 Alvania lactea Mrchaud (Rissoa l. Mrchaud).

(a) Mündungs-, (b) Rückseite. Bei Helgoland leere Schalen. Südliche Form, vom Kanal bis ins Mittelmeer.

3 Manzonia costata J. Adams.

(a) Von der Mündungsseite, (b) von der Rüdkseite gesehen. Leere Schalen bei Helgoland. Norwegische, schwedische, englische Küsten; von Shetlands bis zum Mittelmeer und den Kanaren.

4 Rissoa membranacea J. Adams (Zippora m. J. Adams).

(a) Mündungs-, (b) Rückansicht. Meer- und Brackwasser. Nordsee, westliche Ostsee. Atlantikküsten bis zu den Kanaren, auch Mittelmeer.

5 Cingula (Onoba) striata Montagu (C. semicostata Montagu).

(a) Mündungs-, (b) Rückansicht. Bei Helgoland (aus HernCKE 1894 nach KobelT), "von der Bernaschen Expedition 8 Meilen NW gedredgt". Westliche Ostsee. Europäische Atlantikkïsten, vom Eisneer bis zum Mittelmeer.

6 Cingula (Hyala) vitrea Montagu.

(a) Mündungs-, (b) Rückseite. Englische Ostküsten, Kattegat, norwegische Küsten, europäische Atlantikküsten bis Mittelmeer. 


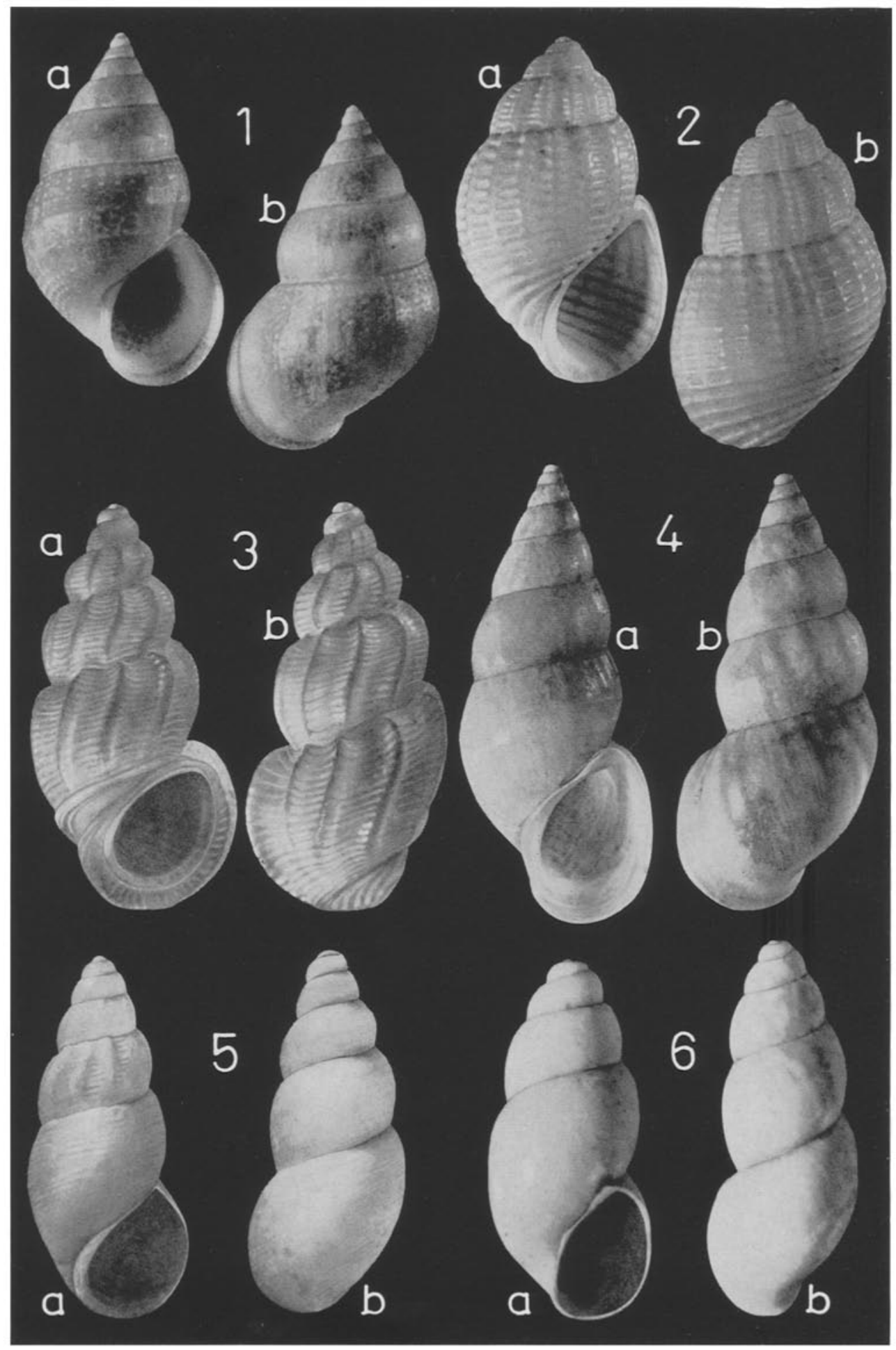




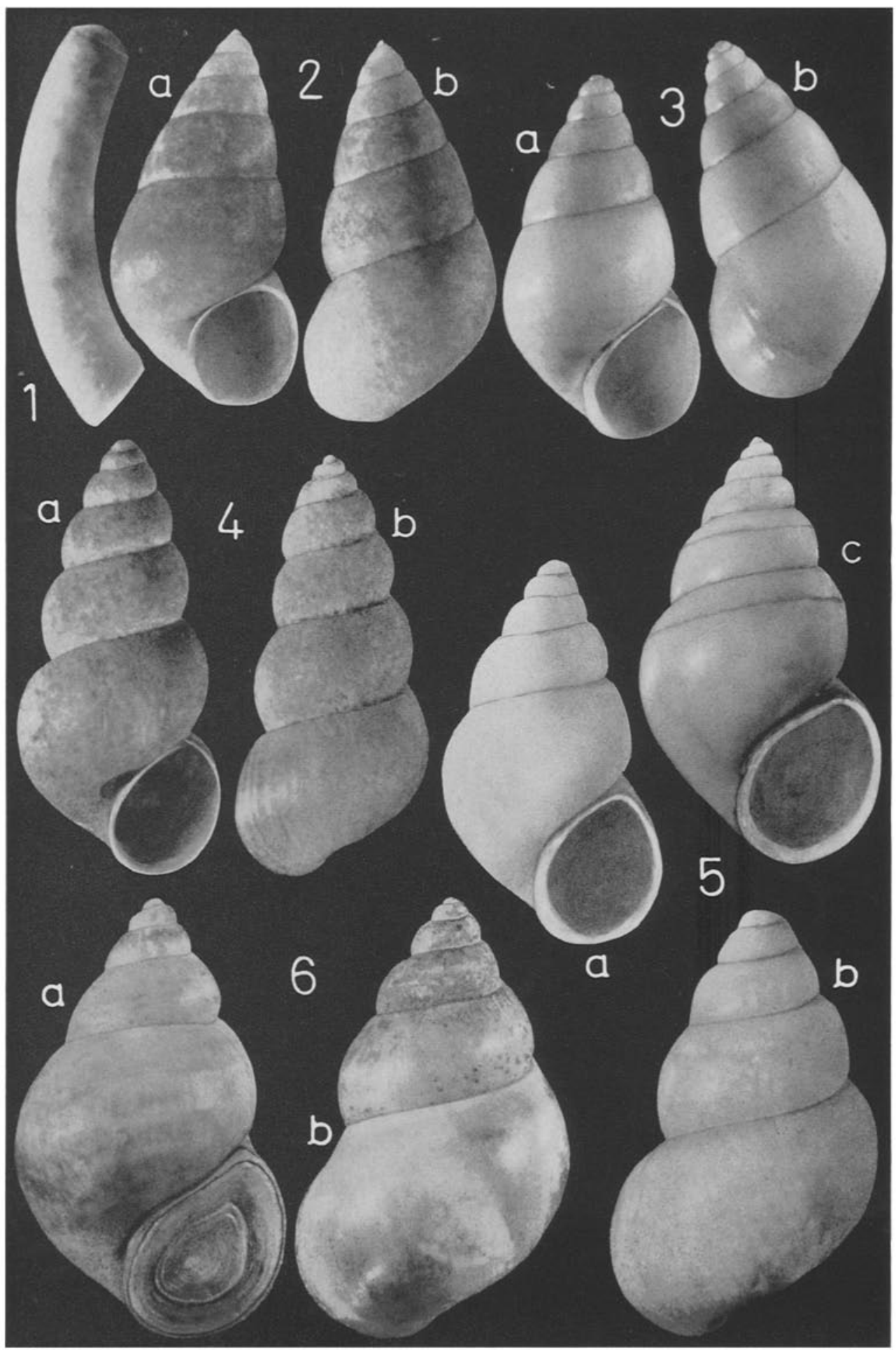

Tafel 8 
Tafel 8

1 Caecum glabrum MoNTAGU.

Bei Helgoland im groben Sand auf dem Amphioxus-Grund. Dänische Küsten, britische Ostküsten, europäische Atlantikküsten bis Mittelmeer.

2 Barleeia rubra ADAMs.

(a) Mündungs-, (b) Rükansicht. Vorkommen bei Helgoland wie Cingula striata (Taf. 7, 5). Atlantische Küsten Europas, Mittelmeer, Kanaren.

3 Hydrobia ulvae Pennant (Paludestrina u. Pennant), Wattschnedke.

(a) Mündungs-, (b) Rückseite. Benötigt höheren Salzgehalt. In der Deutschen Bucht im Schlick 1950 in $10 \mathrm{~m}$ Tiefe bis zu etwa 7000 lebende Tiere auf $0,1 \mathrm{~m}^{2}$. Massenhaft im Schlickwatt (Königshafen List/Sylt). Nach ANkEL (1936) im Brackwasser bis

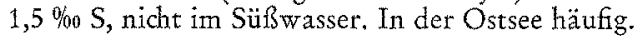

4 Hydrobia stagnalis Baster ( $H$. ventrosa Montagu).

(a) Mündungs-, (b) Rückansicht. In Brackwasser und Flußmündungen, nicht im Meerwasser.

5 Potamopyrgus jenkinsi SmITH (Hydrobia j. SMITH)

(a) Mündungs-', (b) Rückseite, (c) schwach gekielte Form. Im Süß- und Brackwasser, bei noch weniger Salzgehalt als vorige Art.

6 Bitbynia tentaculata LiNNó.

(a) Mündungs-, (b) Rückseite. Im Süß- und Brackwasser. 
Tafel 9

1 Bitbynia leachi SHEPPARD.

(a) Auf die Mündung, (b) auf die Rückseite gesehen. Itn Süß- und Brackwasser.

2 Skeneopsis planorbis FaBRICIUS.

(a) Mindungs-, (b) Nabel-, (c) Apexansicht. Bei Helgoland in Gezeitentümpeln des Felswatts (nach HeIncke 1894 "häufig an Pflanzen"). Nordatlantik, Mittelmeer.

3 Omalogyra (Homalogyra) atomus PHItrppr.

(a) Mündungs-, (b) Basal-, (c) Apexseite. Bei Helgoland an der Niedrigwassergrenze in der oberen Laminarien-Zone. Kieler Bucht. Nördliche Nordsee.

4 Assiminea grayana Fleming.

(a) Mündungs-, (b) Rückansicht. In den Nordseewatten, oberhalb der Hodwasserlinie. Brackwasser.

5 Lacuna divaricata FABRIcrus (L. vincta MonTAGU), Gebänderte Grübchenschnecke. (a) Mündungs-, (b) Rückseite. Bei Helgoland „in ungeheurer Menge überall an Algen, Tangen und Seegras der Tidenregion" (HEnNCke 1894). Bis $20 \mathrm{~m}$ Tiefe, auch auf kiesigem bis steinigem Boden. Kieler Bucht, mecklenburgische Küste. Nördliche Form. Nordatlantik auf der europäischen Seite etwa bis in Höhe der französischen Küsten.

6 Lacuna pallidula DA Costa (Nerita pallidulus DA Costa), Flache Grübchenschnecke. (a) Mündungs-, (b) Rückansicht. Bei Helgoland, bis etwa $15 \mathrm{~m}$ Tiefe, an Algen mit Lacuna divaricata gemeinsam, aber nicht so häuffi. Kieler und Neustädter Bucht. Sonstige Verbreitung etwa wie vorige Art, fehlt jedoch an der holländischen Küste. 
Schnecken deutscher Meeresgebiete und Küstengewässer

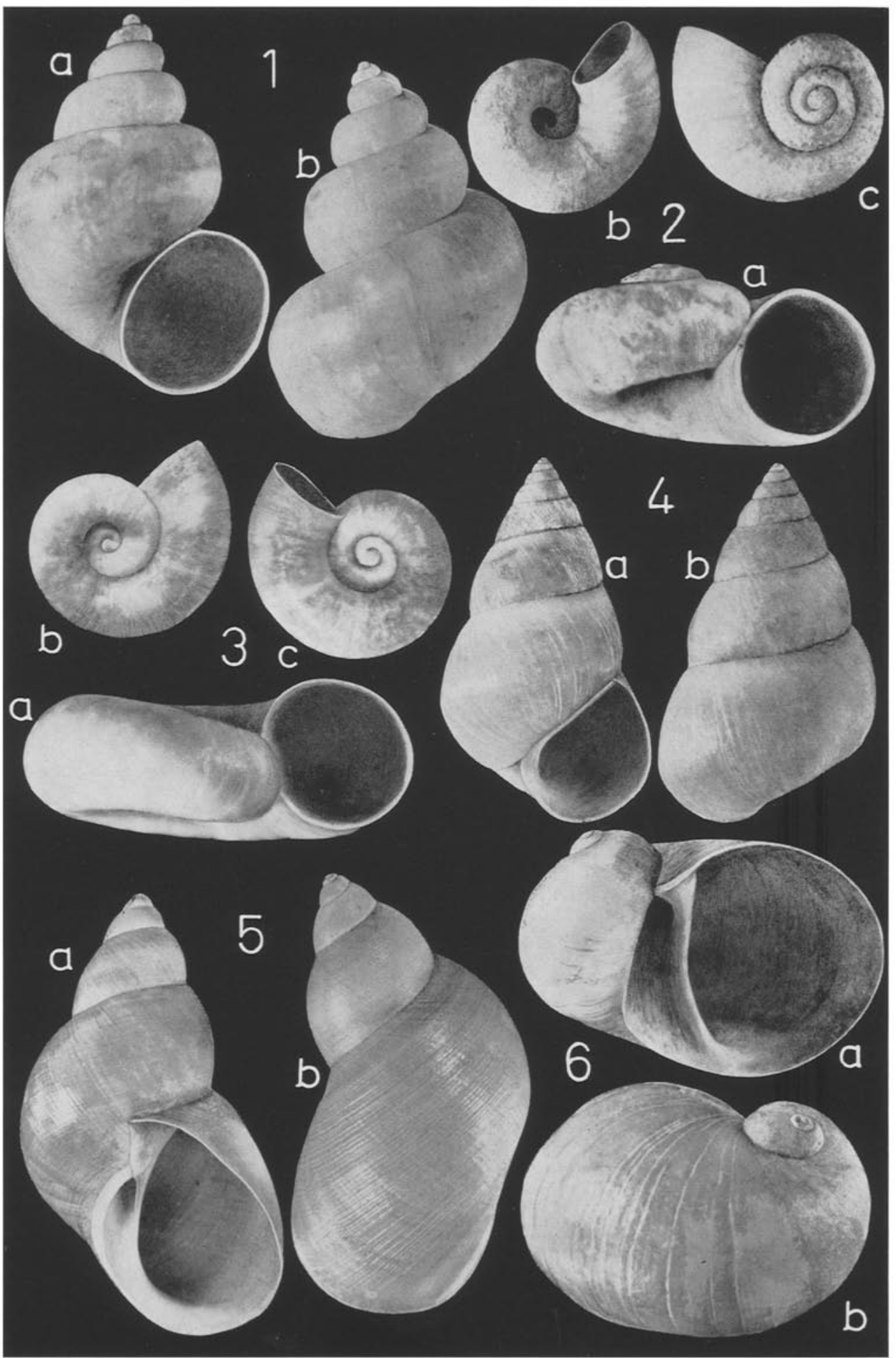

Tafel 9 


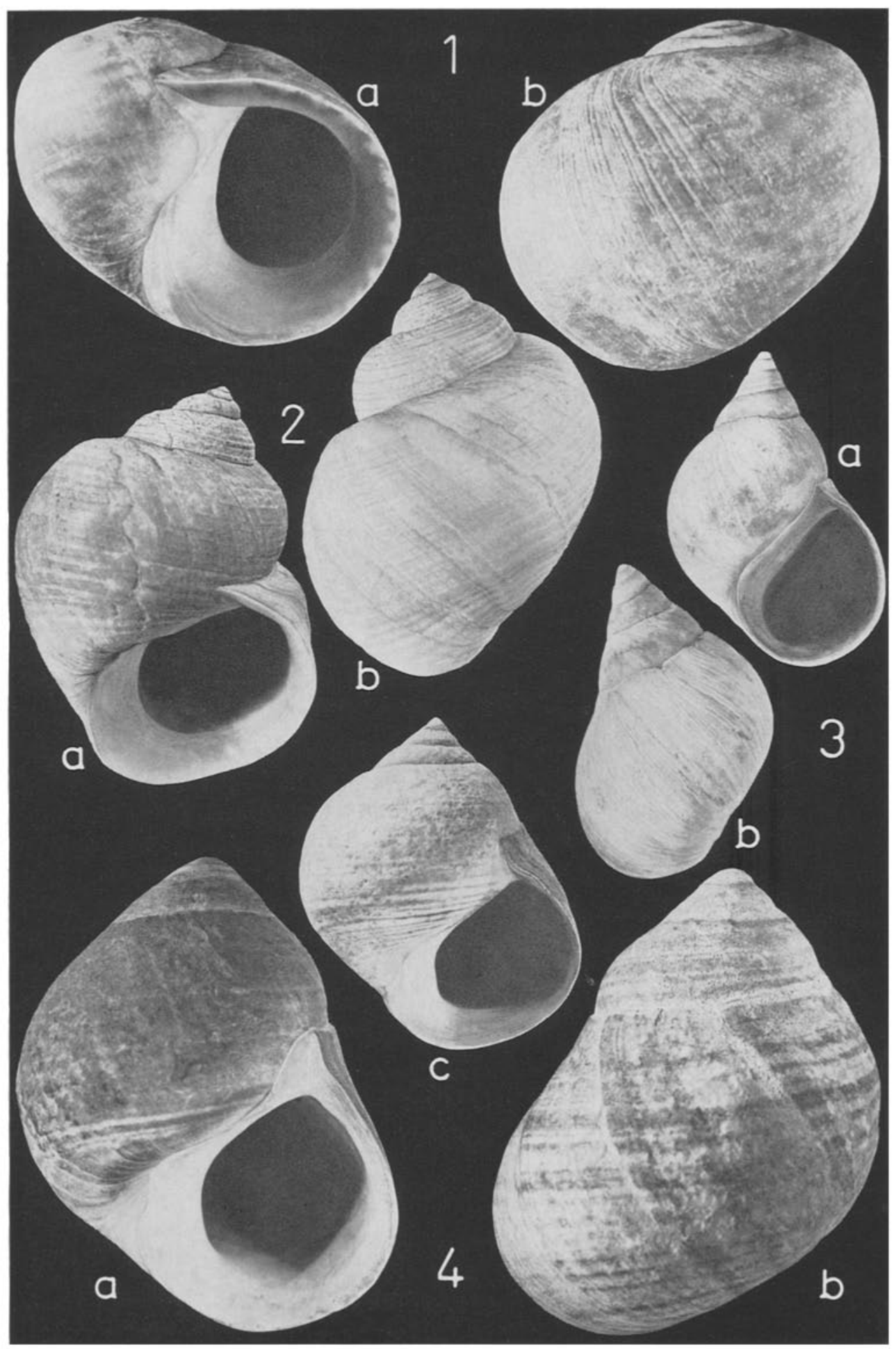

Tafel 10 


\section{Tafel 10}

1 Littorina obtusata Linné, Stumpfe Strandschnecke.

(a) Mündungs", (b) Rückseite. An allen Nordseekïsten, Helgoland, deutsche Ostseeküste. Im Eulitoral lebt die Art von allen Littorinen am tiefsten. Häufig zu finden auf $F$ ucus serratus, im Königshafenwatt bei List/Sylt auf Zostera. Vom Weißen Meer und Island bis in das Mittelmeer.

2 Littorina saxatilis Ouvr, Kleine Strandschnecke.

(a) Mündungs-, (b) Rückansicht. An den Nordseeküsten, Helgoland, westliche Ostsee. Eine sehr variable Art, bei der verschiedenste Subspecies unterschieden werden können. In der Gezeitenzone geht diese Strandschnecke, ebenso wie die folgende Art, am höchsten über die Hochwasserlinie und hält sich in feuchten Gesteinsritzen und Löchern auf. Nordatlantische Küsten.

3 Littorina neritoides LinNé, Spitze Strandschnecke.

(a) Mündungs-, (b) Rückseite. Bei Helgoland an Steinen und in feuchten Vertiefungen über der mittleren Hochwasserlinie im nördlichen Felswatt (vgl. vorige Art). Bei den hier abgebildeten Sdalen handelt es sich um L. neritoides petraea MonTAGr, die Dr. Den Hartog, Leiden, Holland, im Sommer 1960 in einigen lebenden Exemplaren an der "Langen Anna" gefunden hatte. Atlantische Küsten, Mittelmeer, Kanaren.

4 Littorina littorea Linné, Gemeine Strandschnecke.

(a) und (b) dickschalige Gehäuse aus dem Nordostfelswatt bei Helgoland, (c) Schale aus dem Königshafenwatt bei List/Sylt. Sehr variable Form. An allen Nordseeküsten, westliche Ostsee. Geht nicht so hoch über den Wasserspiegel wie die beiden vorigen Arten. Die Schnecken werden von den Helgoländern gegessen (helgoländisch: Hölkers). Nordatlantische Küsten, auf Spitzbergen fehlend, an der Küste der Vereinigten Staaten eingeschleppt. 


\section{Tafel 11}

1 Turritella communis Lamarck, Gemeine Turmschnecke.

(a) Mündungs-, (b) Rückansicht. In der Deutschen Bucht in tieferem Wasser, im Schlick zuweilen sehr häufig mit einer Bestandsdichte von 70 Tieren in einem $0,1-\mathrm{m}^{2-}$ Bodengreifer ( $45 \mathrm{~m}$ Tiefe). Bei Helgoland meist nur leere Schalen, am häufigsten in der Tiefen Rinne. Nordsee, europäische Küsten, Mittelmeer.

2 Triphora perversa LinNé.

(a) Mündungs-, (b) Rückseite. Kieler Bucht, auf Algen. Leere Schalen bei Helgoland. An den Küsten der mittleren und nördlichen Nordsee, europäische Atlantikküsten. bis Kanaren, auch Mittelmeer.

3 Bittium reticulatum DA CosTA, Kleine Gitterschnecke.

(a) Mündungs-, (b) Rückseite. Nordsee, in dänischen Gewässern, Kieler Bucht. Im Angespül an geeigneten Stellen in Wattgebieten (zum Beispiel Lister Haken/Sylt) sehr häufig. Europäische Atlantikküste bis zu den Kanaren. Mittelmeer, Schwarzes Meer.

4 Scala clathrus Linné (Clathrus cl. Linné, Scalaria communis Lamarck), Unechte Wendeltreppe.

(a) Mündungs-, (b) Rückseite. Selten im schillhaltigen Schlick bei Helgoland, häufig leere Schalen in der T'iefen Rinne. Nordsee, atlantische Küsten von Finnmarken bis Kanaren, Mittelmeer.

5 Scala turtonis Turton [Scala (Fuscoscala) tenuicosta Mickaud].

(a) Mündungs- und (b) Rückansicht. Bei Helgoland noch nicht nachgewiesen. Holländische und britische Ostküsten, Doggerbank, Kattegat, Bohuslän. Europäische Atlantikküsten bis Madeira, Mittelmeer. 


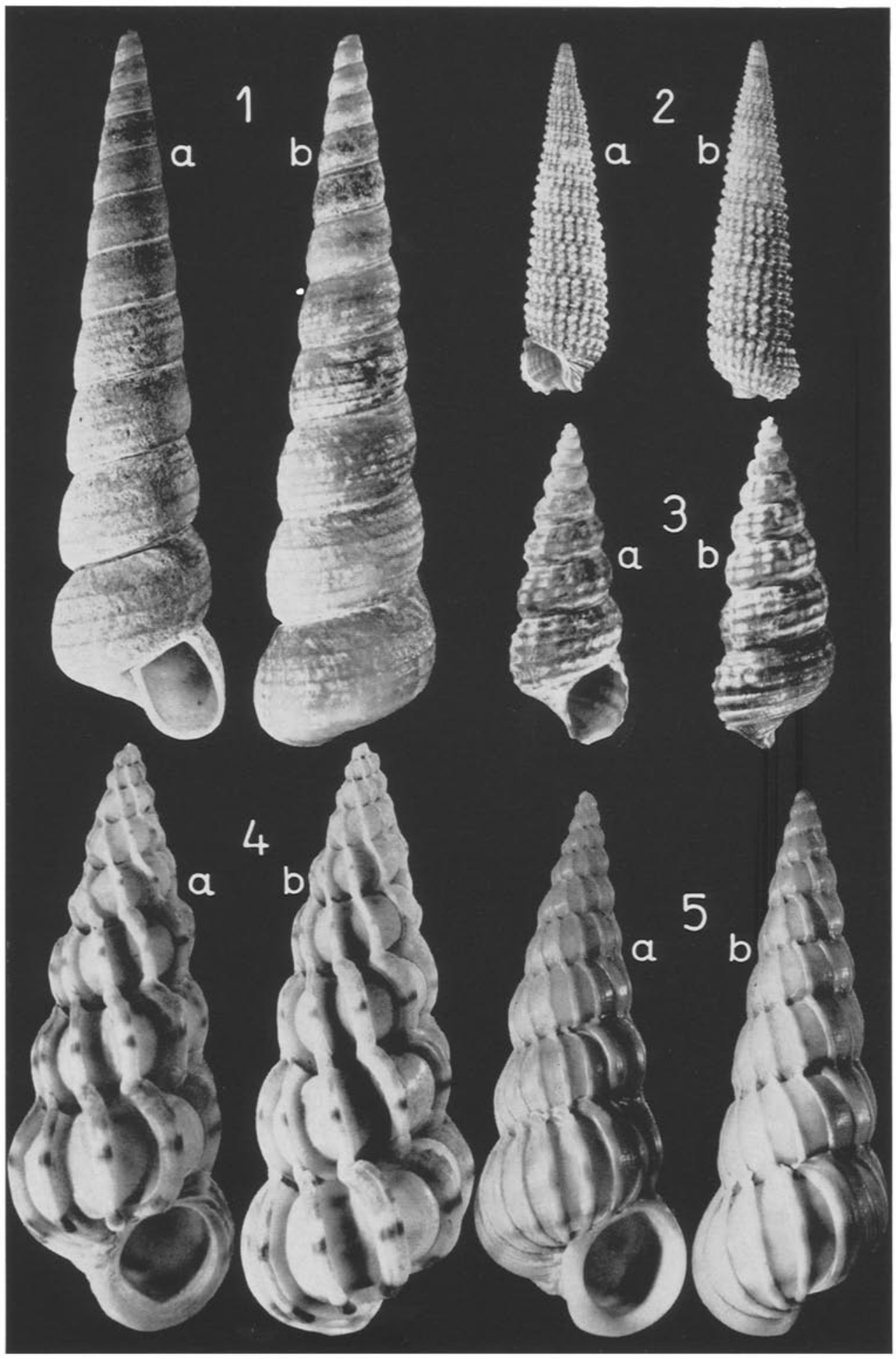




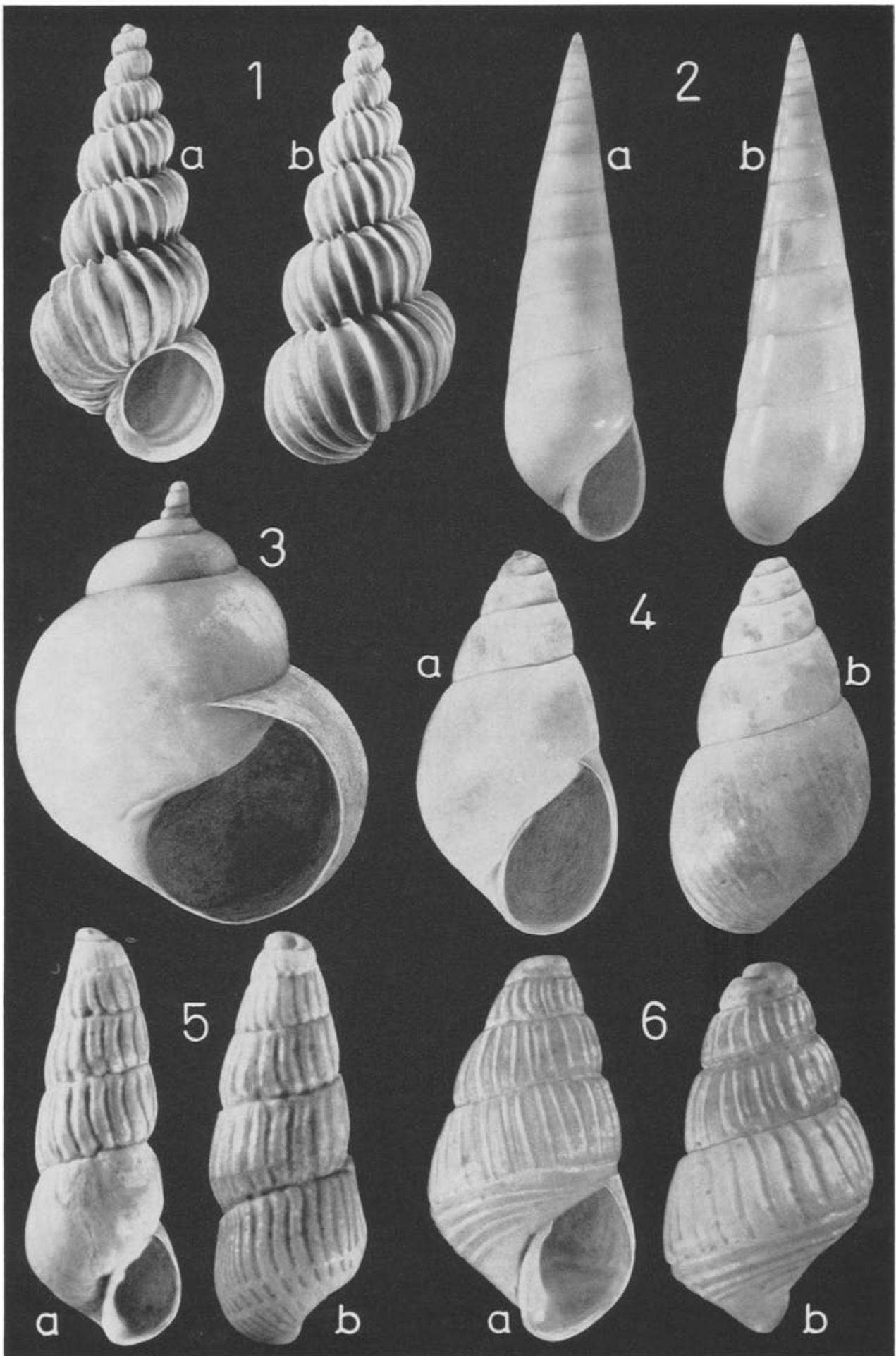

Tafel 12 


\section{Tafel 12}

1 Scala clatbratula Kanmacher (Clatbrus clathratulus Adams), Weiße Wendeltreppe. (a) Mündungs-, (b) Rückseite. Nach HenNCKe (1894) "nicht selten auf dem Pümpgrunde der Tiefen Rinne". Die Bodengreiferuntersuchungen von CASPERS (1938) und Beobachtungen ab 1949 erbrachten bisher keinen Lebend-Fund. Leere Gehäuse gelegentlich im Siebrest der Proben aus der Tiefen Rinne. Europäische Atlantikküsten bis ins Mittelmeer.

2 Eulima alba Da CosTa (Eu. polita LinNÉ).

(a) Mündungs-, (b) Rückansicht. Zuweilen leere Gehäuse im Siebrest von Bodengreiferproben aus der Helgoländer Tiefen Rinne. Atlantikküsten Europas, Mittelmeer.

3 Pelseneeria stylifera Turton (Rosenia st. Turton).

Nur auf lebenden Seeigeln, zwischen deren Stacheln (auch auf Echinus esculentus).

4 Bracbystomia rissoides Hanley (Odostomia $r$. Handey).

(a) Mündungs-, (b) Rückseite. Nordsee, Kieler Bucht. Parasitiert auf Mytilus edulis. Die Schnecken sitzen am Schalenrand und saugen mit weit ausgestrecktem Rüssel am Mantelrand der Miesmuschel. Europäische Atlantikküisten, Mittelmeer.

5 Parthenina obtusa Brown (Chrysallida interstincta Montagu).

(a) Mündungsansicht, (b) Rückseite. Bei Helgoland gelegentlich leere Gehäuse. „Eine leere Schaale im Nordhafen gedredgt. Kommt sicher auch lebend dort vor" (HEINCKE 1894). Lebend-Vorkommen bisher nicht festgestellt. Mittlere und nördliche Nordsee. Nordatlantik bis zum Mittelmeer.

6 Partulida spiralis Montagu (Chrysallida sp. Montagu, Odostomia sp. Montagu). (Bei ANkel 1936 wohl versehentlich "Partidula").

(a) Mündungs-, (b) Rückseite. Nach HEINCKE (1894) "Im Nordhafen zwischen Algen nicht selten ". Bisher nur vereinzelt leere Schalen bei Helgoland im Siebrest von Bodengreiferproben. Mittlere und nördliche Nordsee. Europäische Atlantikküsten bis Gibraltar. 


\section{Tafel 13}

1 Turbonilla lactea Linné.

(a) Mündungs-, (b) Rückansicht. Bei Helgoland in der Tiefen Rinne mitunter leere Gehäuse im Siebrest von Bodengreiferproben. Nördliche Nordsee, atlantische Küsten bis zu den Kanaren, Mittelmeer.

2 Turbonilla rufa Phipipri (Pyrgiscus rufus Phiripr).

(a) Mündungs-, (b) Rückseite. Mittlere und nördliche Nordsee. Europäische Atlantikkïsten bis Madeira, Kanaren, auch Mittelmeer.

3 Eulimella commutata Monterosato (Odostomia acicula Philippi, Eu acicula PhILIPPI?).

(a) Mündungsseite, (b) Rückansicht. Die abgebildeten Schalen stammen von jüngeren Tieren, um das zur Gehäuseachse schief stehende heterostrophe Embryonalgewinde zu veranschaulichen. Bei Helgoland „leere Schaalen im NNW in 15 Faden Tiefe auf Schlickgrund gedredgt" (HEINCKE 1894). Nach brieflicher Mitteilung von Dr. JAECKEL, Kiel, "nördlich Kieler Bucht selten". Mittlere und nördliche Nordsee. Atlantikküsten Europas von den Hebriden bis ins Mittelmeer.

4 Lunatia montagui Forbes (Natica m. Forbes).

(a) Mündung mit Operculum und Nabel, (b) Rückseite. Das von AnKel (1936), Brohmer (1955) und StrESEMANN (1957) angegebene Vorkommen "Deutsche Bucht" ist zu berichtigen. Die Art wird nicht erwähnt bei HeINCKe (1894), CAspers (1938), HAGMerer (1951). Nach eigenen Bodenfaunauntersuchungen in dem Gebiet (kontinuierlich durchgeführt seit 1949) konnte $L$. montagui auch bei Helgoland nicht gefunden werden. Mittlere und nördliche Nordsee, dänische Gewässer. Atlantische Küsten bis Gibraltar, Mittelmeer.

5 Lunatia nitida Donovan (Natica pulchella Russo, $N$. poliana alderi Forbes), Glänzende Nabelschnecke.

(a) Mündungs-, (b) Rückseite. In der Deutschen Bucht und bei Helgoland häufig in sandigem bis schlickigem Boden. Da sich die Schnecken räuberisch hauptsächlich von lebendfrischen Muscheln ernähren, hängt die Abundanz vom Nahrungsangebot ab. In guten Muscheljahren sehr häufig. Die Beutetiere werden von den Schnecken im Boden angefallen, die Schale mit der Radula durchbohrt und der Weichkörper herausgeholt und verzehrt. Weit verbreitet: Nordsee (nach ANKEL 1936 im Limfjord fehlend), an den westatlantischen Küsten von den Lofoten, Faröer bis Afrika, auch im Mittelmeer. 


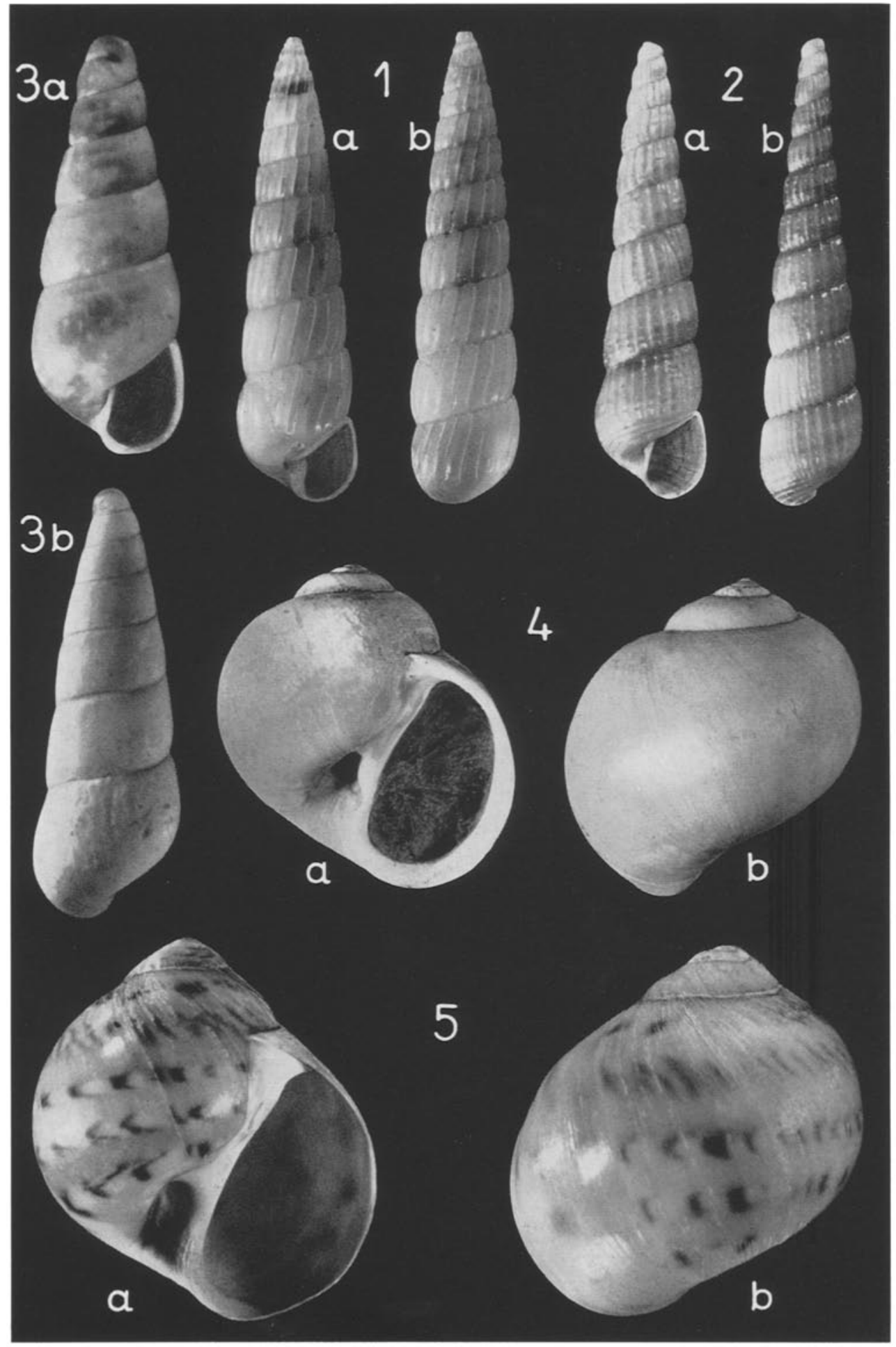




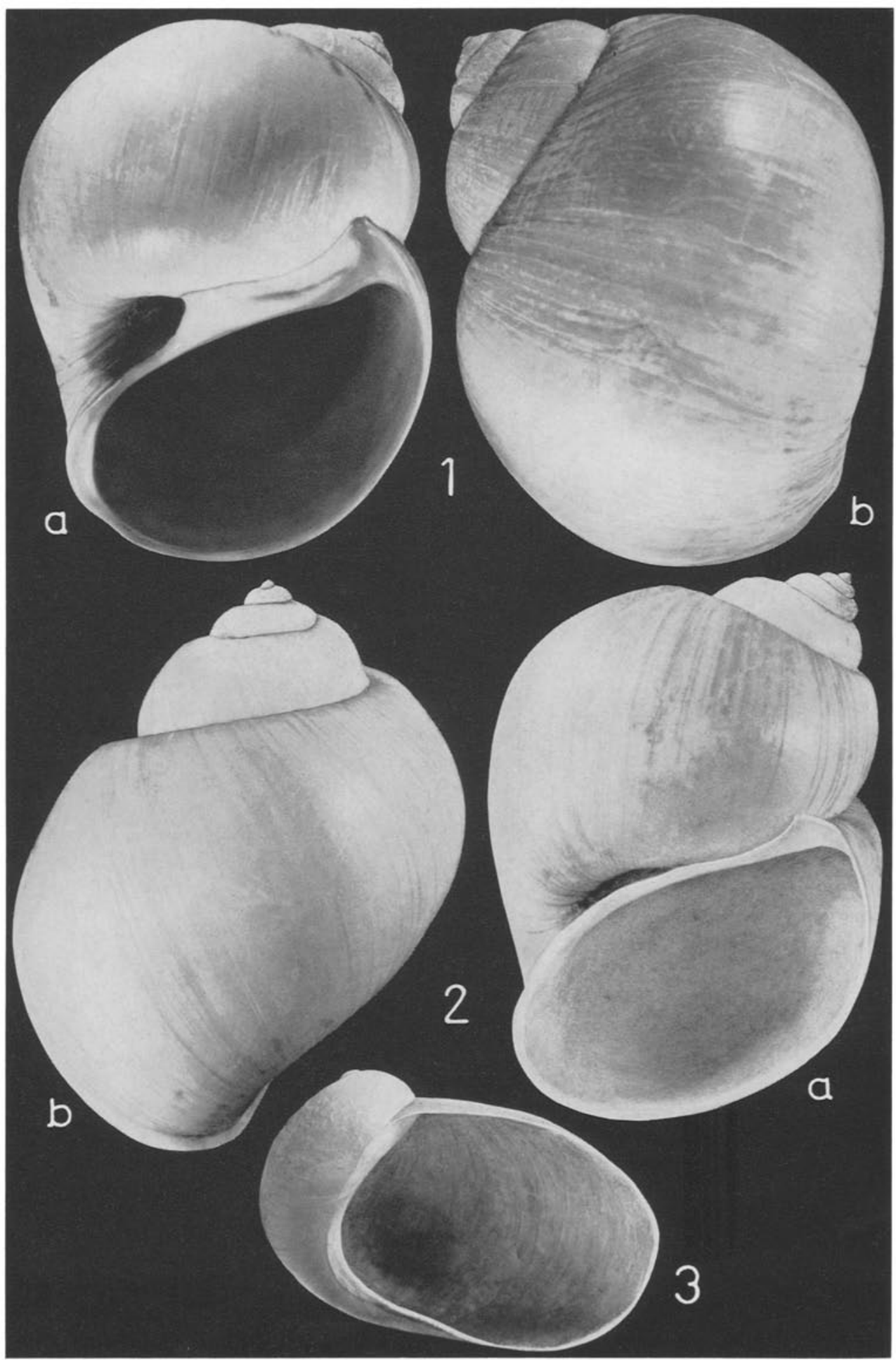

Tafel 14 
Tafel 14

1 Lunatia catena DA Costa (Natica catena DA Costa, N. monilifera Lamarck), Große Nabelschnecke.

(a) Mündungs-, (b) Rückansicht. In der Deutschen Bucht nur in tieferem Wasser NW von Helgoland in sandigem bis schlickigem Boden. In unmittelbarer Nähe von Helgoland keine Lebendfunde. Häufig sind leere Gehäuse von Eupagurus bernhardus bewohnt. Bei älteren Schalen meist Bewuchs mit Hydractinia echinata. Nahrungserwerb und -aufnahme wie bei Lunatia nitida. Boreal-mediterrane Form. Nicht bis zur norw egischen Küste. Britische Atlantikküsten bis ins Mittelmeer.

2 Amantopsis islandica GmeLin (Natica belicoides Johnston).

(a) Mündungs-, (b) Rückseite. Mittlere und nördliche Nordsee, dänische Gewässer, nicht im Limfjord. Bis Spitzbergen, Grönland, Eismeerküsten.

3 Lamellaria perspicua Linné (L. tentaculata Montagu).

Bei Helgoland, nicht häufig, unter Steinen in Felswatt-Tümpeln an der Niedrigwasserlinie. Weit verbreitet in vielen Meeresteilen der nördlichen Hemisphäre. 


\section{Tafel 15}

1 Velutina velutina O. F. Müller (V. laevigata Pennant).

(a) Mündungs-, (b) Rückseite. Bei Helgoland in der Tiefen Rinne bewohnt die Art nach HerNcke (1894) "schlickigsandige Gründe mit vielen Ascidien (Phallusia virginea $)^{\text {‘. }}$. Dient (1956) wies nach, daß die Schnecke in der Kieler Budht mit der Ascidie Styela coriacea lebt. Velutina bohrt ein Loch in die Ascidie und zehrt sie mit ihrem Rüssel auf. Weiterhin wird die Ascidie für die Fortpflanzung benutzt. Die Raubschnecke legt den Laich an den Mantel der Ascidie, das Gelege wird vom Mantel als Kokon überwachsen, aus dem die fertigen Veligerlarven schlüpfen. Mittlere und nördliche Nordsee, Nordatlantik, nordamerikanische Küsten, europäische Atlantikküsten von Belgien bis zum Mittelmeer.

2 Trivia monacba Da Costa (T. europaea Montagu).

(a) Mündungs-, (b) Rückseite. Im Siebrest der Bodengreiferproben aus der Helgoländer Tiefen Rinne gelegentlich leere Schalen. Mittlere und nördliche Nordsee, norwegische, schwedische Westküsten. Europäische Atlantikküsten von den Faeröern bis ins Mittelmeer.

3 Crepidula fornicata LinnÉ, Pantoffelschnecke.

(a) Unterseite (Mündung), (b) Rückansicht, (c) Kettenbildung. Flachwasserform auf Steinen, Muschelschalen der Austernbänke, dort Nahrungskonkurrent. Eingeschleppte Art: 1880 mit amerikanischen Austern nach England, 1929 auf den holländischen Bänken, seir 1934 auf den Austernbänken bei List/Sylt, nach 1949 vereinzelt auch bei Helgoland. Die Kette dient der geschlechtlichen Fortpflanzung der fast sessilen Tiere, wobei in der Aufeinanderfolge der Kettenbildung die als Männchen sich ansetzenden Schnecken das darunter befindliche Weibchen begatten und sich später in Weibchen umwandeln. 


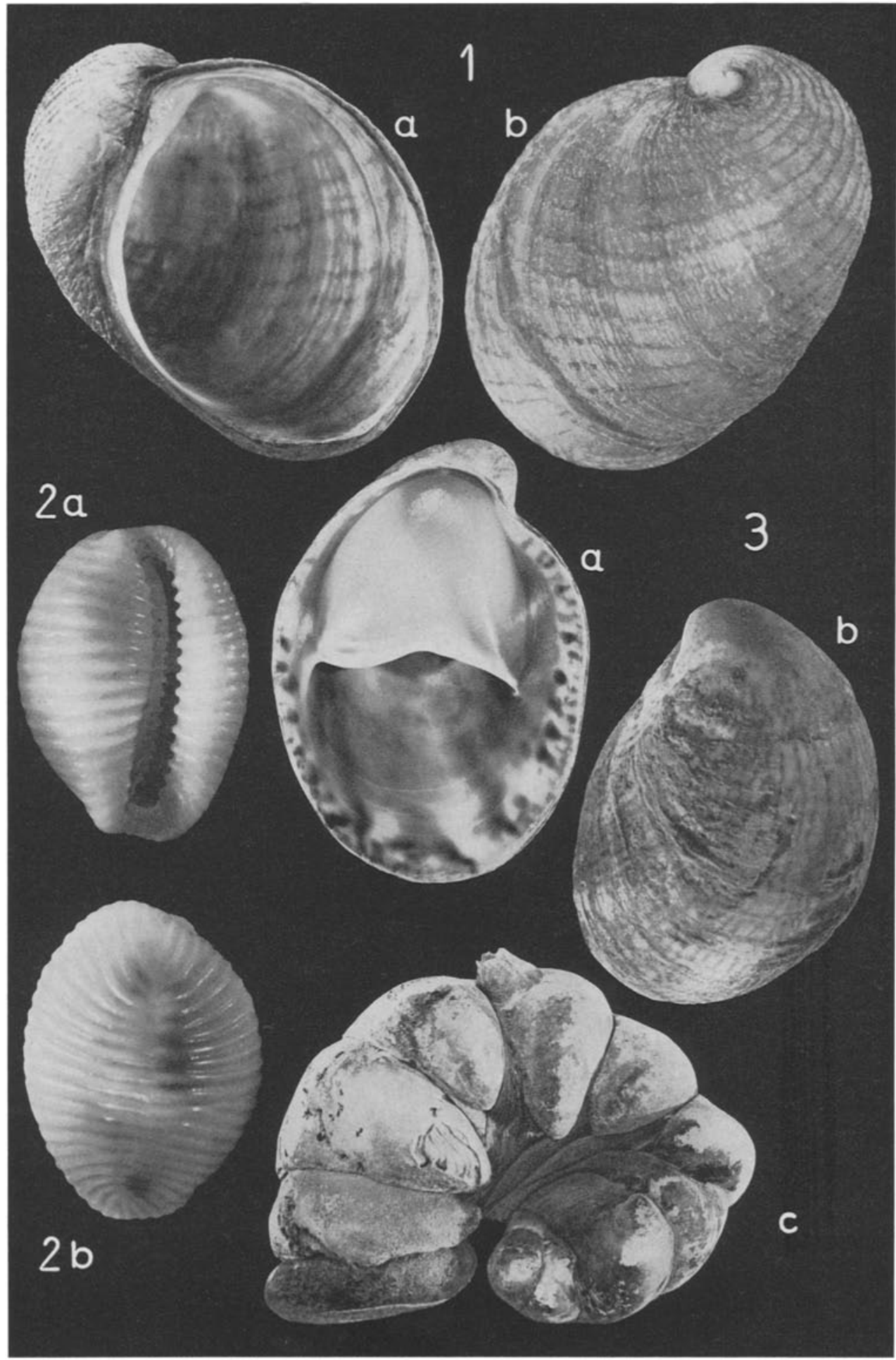

Tafel 15 


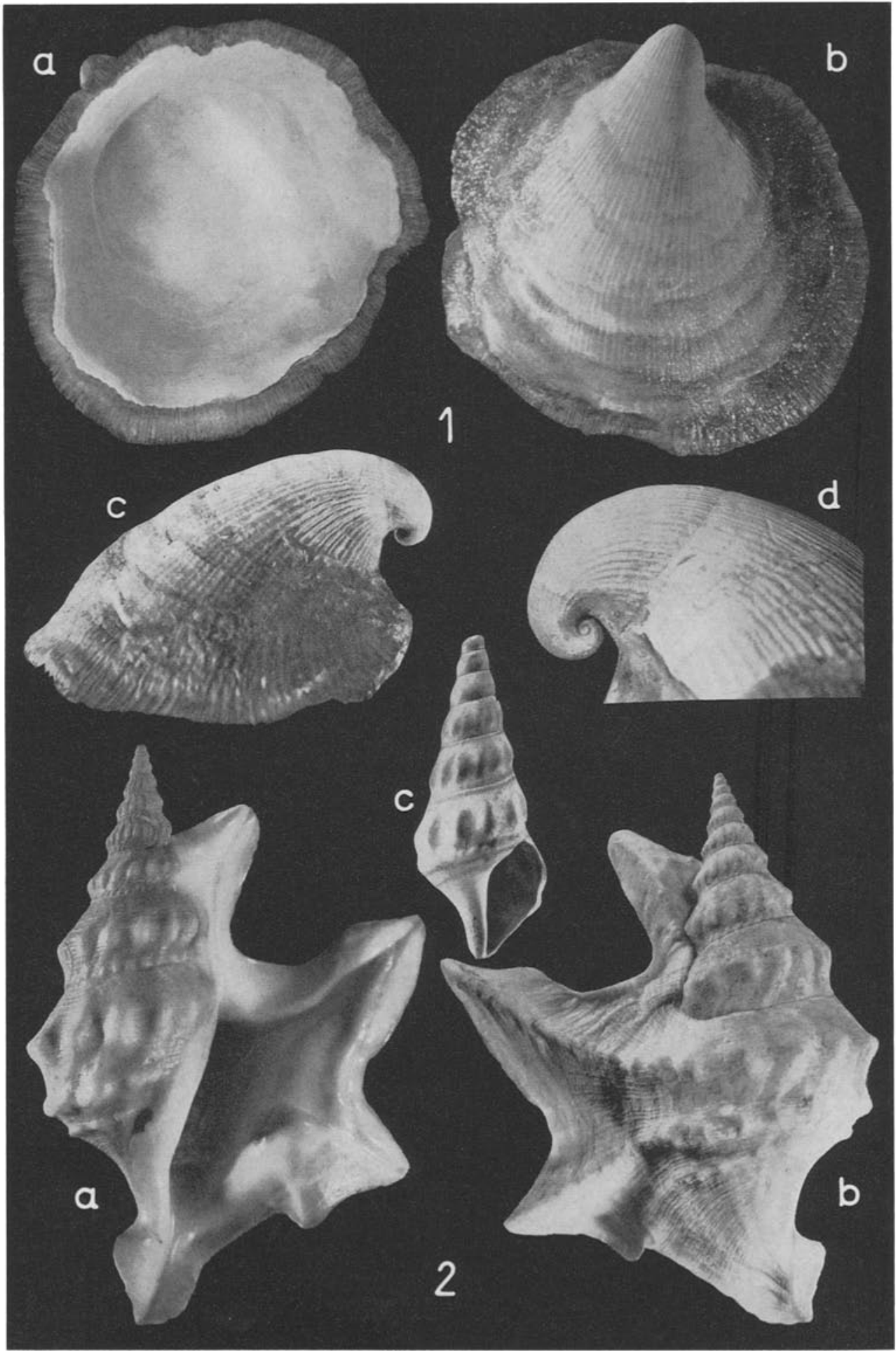

Tafel 16 


\section{Tafel 16}

1 Capulus bungaricus LiNné.

(a) Innen-, (b) Oberseite, (c) von der linken und (d) von der rechten Seite auf den Apex gesehen. Nördliche Nordsee. An Steinen und Muschelschalen, besonders an Pecten opercularis (ANkel 1936). Nach einer 1960 erhaltenen brieflichen Mitteilung von Prof. Thorson lebt im nördlichen Kattegat im Schlick Capulas in einer Zwergform ( 4 bis $5 \mathrm{~mm} \varnothing$ ) als Kommensale mit Turritella communis. Die Tiere sitzen in der Nähe der Einströmöffnung der Mantelhöhle des Wirtes und nutzen den Wasserstrom für die Ernährung und Atmung aus. Capulus ist bei dieser Größe bereits geschledhtsreif. Europäische Atlantikküsten von den Lofoten und Süd-Island bis ins Mittelmeer.

2 Aporrhais pespelecani LunNé, Pelikanfuß.

(a) Mündungs-, (b) Rückansicht, (c) häufig im Angespül zu findende Gehäuse von jüngeren Tieren ohne flügelartig erweiterten Mündungsaußenrand. Sehr variabel in der Ausbildung der fingerförmigen Fortsätze des Außenrandes bei adulten Schnecken. Lebend-Funde in der Deutschen Bucht und bei Helgoland sehr selten. Während der Bodenfaunauntersuchungen ab 1949 konnte nur ein kleines lebendes Exemplar in der Tiefen Rinne gefunden werden. Nach anhaltendem, heftigem NW-Sturm häufiger leere Gehäuse yon adulten Schnecken im Spülsaum yon Sylt. Nordsee, holländische und belgische Küsten. Europäische Atlantikküsten von Island bis ins Mittelmeer. 


\section{Tafel 17}

1 Tritonalia erinacea LrNnÉ (Ocinebra e. LinNÉ), Stachelschnedke.

(a) Mündungsseite, Siphonalrinne hier offen, (b) Rückansicht. Raubschnecke, die Muscheln, vor allem Austern, Balanus anbohrt und ausfrißt. Die zu den Muricidae gehörenden Schnedkenarten (Taf. 17, 1 bis Taf. 18,1) sondern aus der Hypobranchialrinne eine Flüssigkeit $a b$, die im Sonnenlicht eine purpurne oder scharlachrote Farbe annimmt; im Altertum zum Färben von Stoffen verwandt. Englische Ostküsten, Kattegat. Europäische Atlantikküsten bis Mittelmeer, Schwarzes Meer.

2 Urosalpinx cinerea SAY, Austernbohrer.

(a) Mündungs-, (b) Rückansicht. Wie Crepidula fornicata mit amerikanischen Austern eingeschleppt. Seit 1920 auf den ostenglischen Bänken sehr schädlich, bohrt Austern an.

3 Trophonopsis muricatus MonTagu.

(a) Mündungs-, (b) Rückseite. Auf felsigem und steinigem Boden, von der Laminarien-Zone bis etwa $275 \mathrm{~m}$ Tiefe. Mittlere und nördliche Nordsee. Europäische Atlantikküsten bis ins Mittelmeer.

4 Tropbonopsis clatbratus LINNÉ.

(a) Mündungs-, (b) Rüdkansicht. Vorkommen nördlicher als vorige Art. Auch amerikanische Küste, Grönland, Kanada bis Massachusetts. 


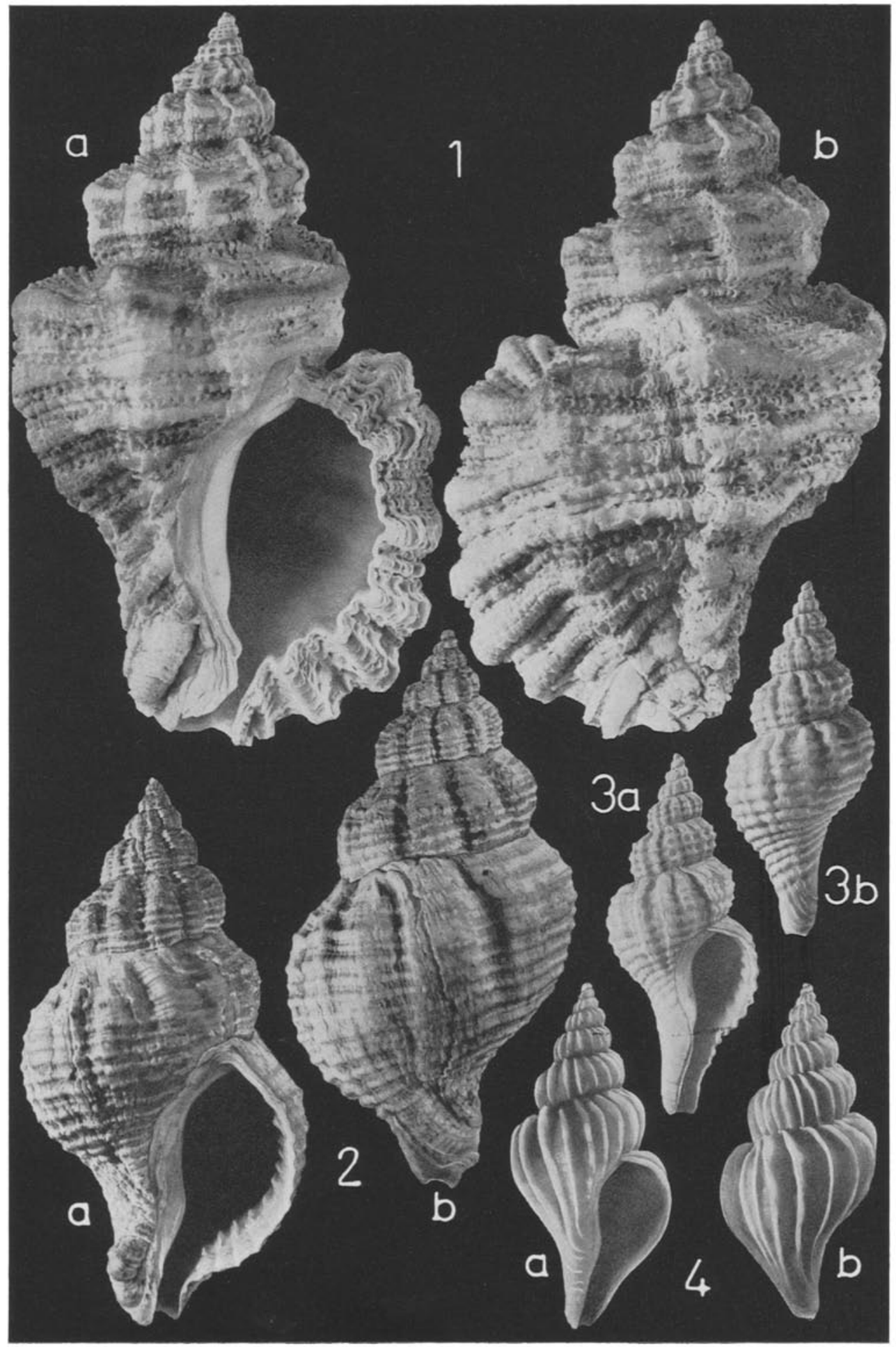




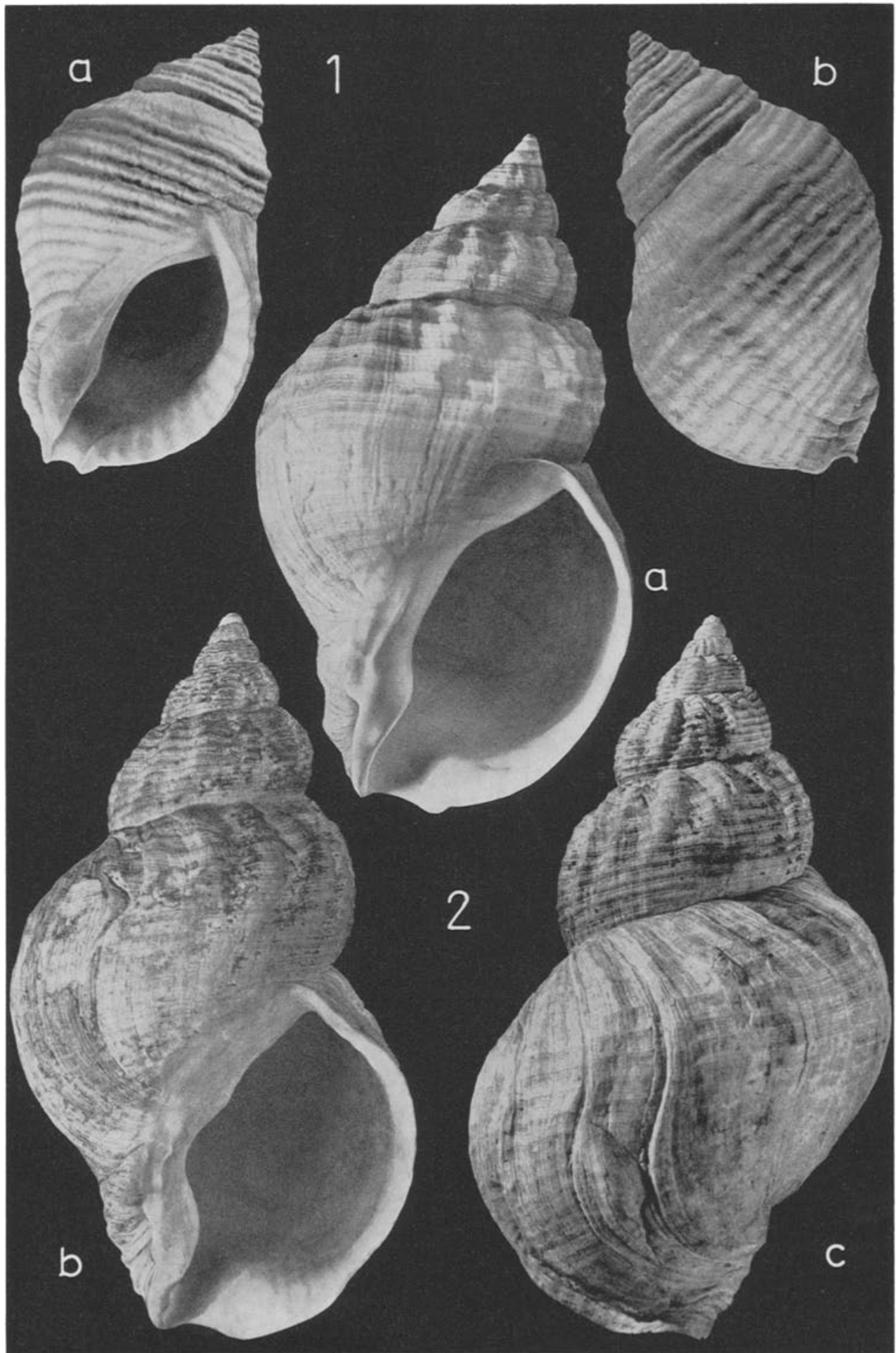

Tafel 18 


\section{Tafel 18}

1 Nucella lapillus LnNé (Purpura l. LInNÉ), Nordische Purpurschnecke.

(a) Mündungs-, (b) Rückansicht. Im Felswatt bei Helgoland häufig auf Steinen in der Brandungszone. Bohrt vor allem Balanus (Seepocken), auch Mytilus (Miesmuscheln) mit der Radula an, um deren Weichkörper aufzuzehren. Bereits die frisch aus den Eikapseln geschlüpften jungen Schnecken bohren sich sofort gegenseitig an (nach eigenen unveröffentlichten Aquariumsbeobachtungen). Im westlichen Teil der mittleren und nördlichen Nordsee. Amerikanische und europäische Küsten des Nordatlantik.

2 Buccinum undatum LinNÉ, Wellhornschnecke.

(a) Mündungsansicht einer dünnwandigen und gleichmäßig skulptierten Schale aus dem Nordsylter Wattenmeer, (b) und (c) dickschalige Gehäuse aus der Brandungszone bei Helgoland. In der Nord- und westlichen Ostsee auf steinigem, sandigem bis schlickigem Boden, im Brackwasser bis etwa $14 \% \mathrm{~S}$. Schale in der Wandstärke und in der Skulptur sehr variabel. In unseren Gebieten die am häufigsten vorkommende größte Schneckenart. Lebt unterhalb der Niedrigwasserlinie. Aas- und Fleischfresser; kann, wie auch die anderen Species der Familie, nicht bohren. Leere Gehäuse werden meist von Einsiedlerkrebsen (Eupagurus) bewohnt, so von den Helgoländern als "Hummerkoxen" bezeichnet. Nordatlantische Ost- und Westküsten. 


\section{Tafel 19}

1 Neptunea antiqua LiNNÉ (Fusus antiquus LnNNÉ, Chrysodomus antiquus LiNNé, Gemeine Spindelschnecke.

(a) Mündungs-, (b) Rüdkansicht. Nordsee, in unmittelbarer Nähe ron Helgoland selten, häufiger im Schlick der Fischfangplätze NW der Insel. Kieler und Travemünder Bucht. Europäische Atlantikküsten bis zur Biskaya.

2 Volutopsius norvegicus Chemntrz (Fusus n. Chemnitz).

(a) Mündungs-, (b) Rückseite. Westküsten der Nordsee, Doggerbank, norwegische Nordküsten, Spitzbergen, Grönland, Island. 


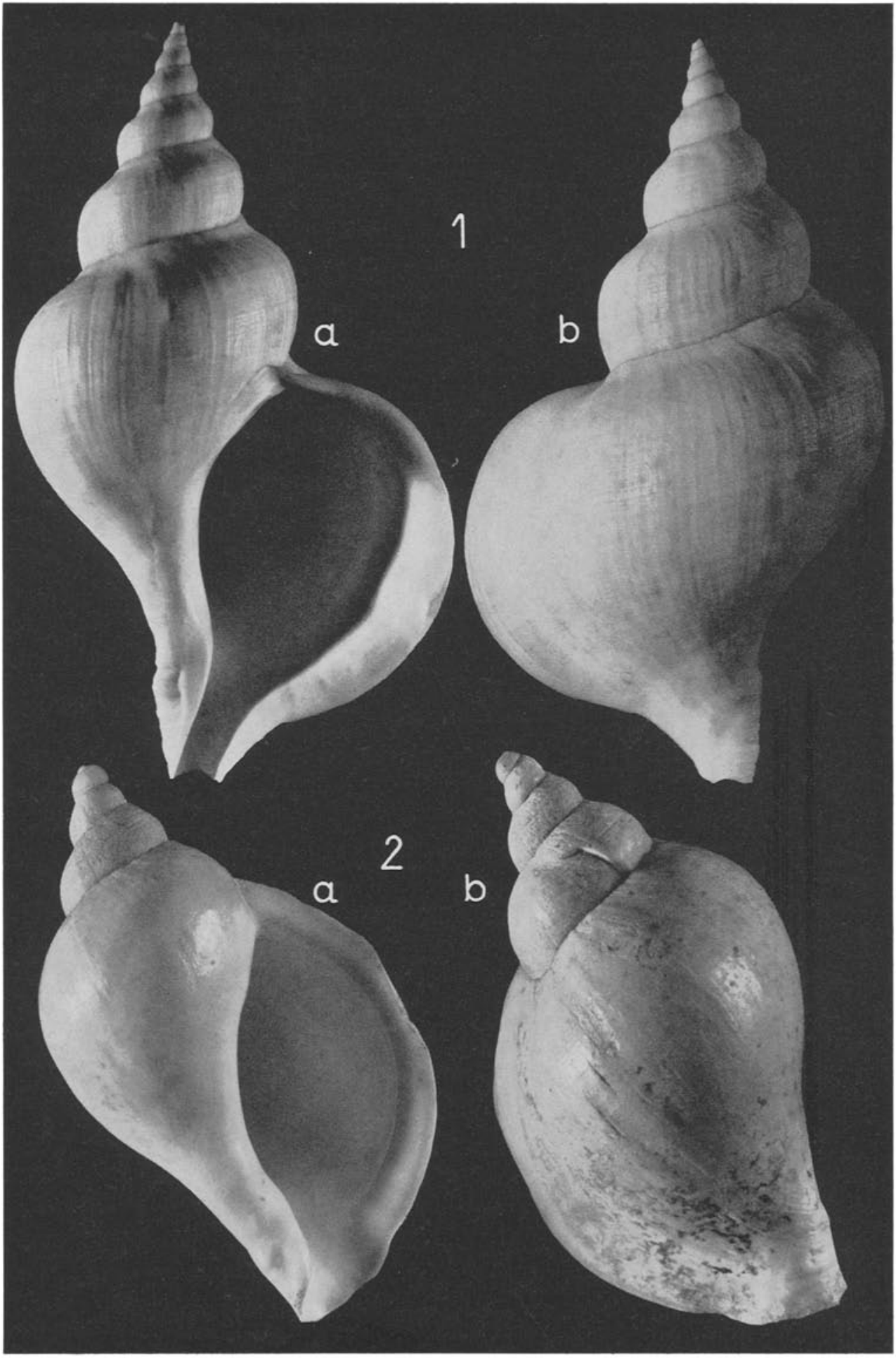

Tafel 19 


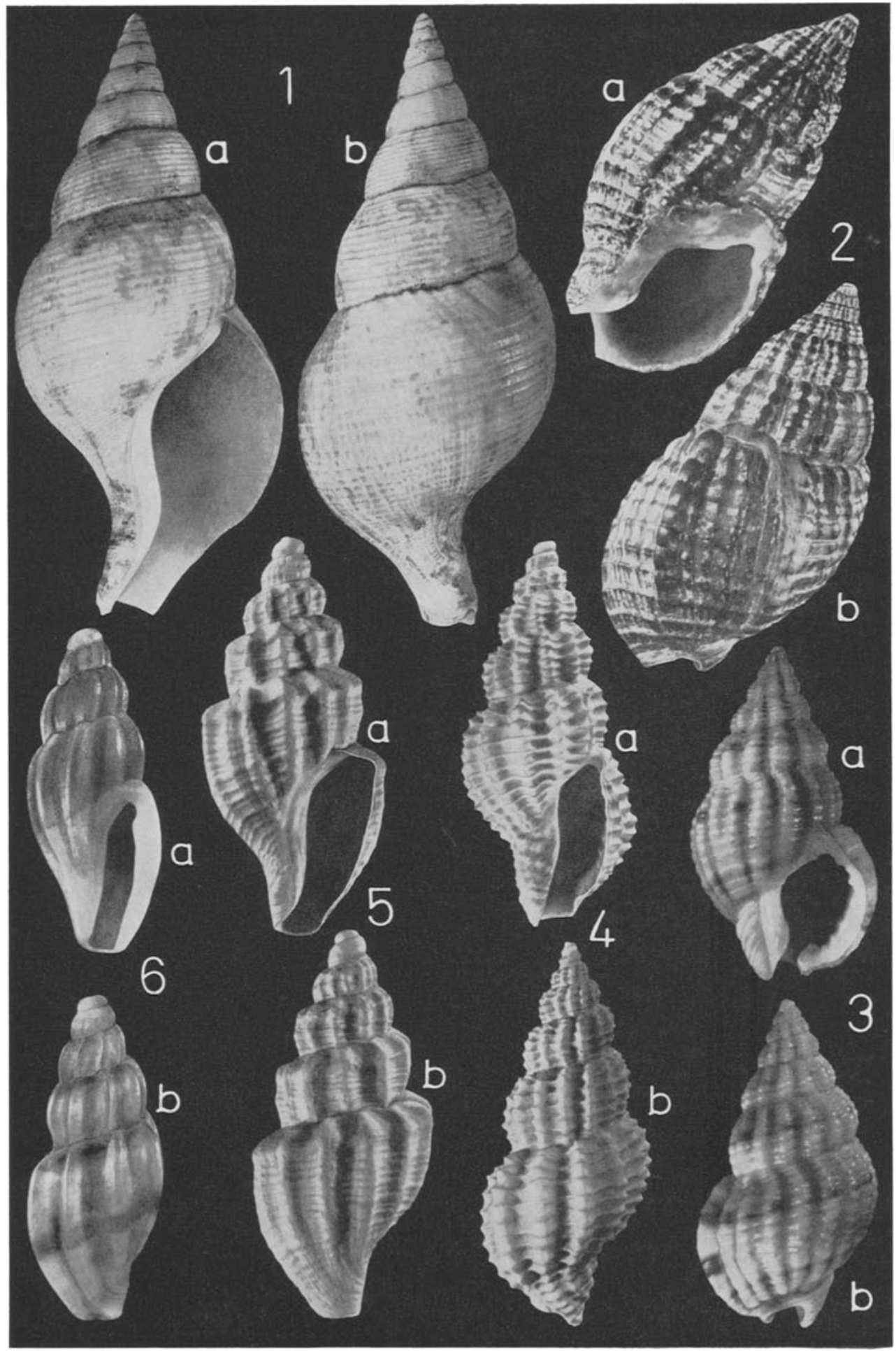


Tafel 20

1 Sipho gracilis DA Costa (Colus g. DA Costa).

(a) Mündungs-, (b) Rückansicht. Leere Schalen von jungen Tieren mitunter im Siebrest von Bodengreiferproben aus der Helgoländer Tíefen Rinne, lebend bisher nicht festgestellt. Nordsee, Nordatlantik, auf der europäischen Seite bis französische Westkiiste.

2 Nassarius reticulatus LuNNÉ (Nassa reticulata LunNÉ), Netzreusenschnecke.

(a) Mündungs-, (b) Rückseite. Im Wattenmeer der Deutschen Bucht in sandigen bis schlicksandigen Böden. Nicht bei Helgoland. Nordsee, Kieler Bucht, im Brackwasser bis $16 \% \mathrm{~S}$. Atlantische europäische Küsten bis ins Mittelmeer, Schwarzes Meer.

3 Nassarius incrassatus STRöm (Nassa incrassata STRöm), Dickschalige Netzreusenschnecke.

(a) Mündungs-, (b) Rückansicht. Leere Schalen im Siebrest von Bodengreiferproben aus der Helgoländer Tiefen Rinne, gelegentlich auch im Angespül am Strand der Düne. Westseite der Nordsee an der holländischen und englischen Ostkïiste, Doggerbank. Norwegische und schwedische Küsten. Europäische Atlantikküsten von Island bis Azoren, Mittelmeer.

4 Pbilbertia linearis Montagu (Defrancia l. Montagu).

(a) Mündungs-, (b) Rückseite. Nach HEINCKE (1894) bei Helgoland „häufig auf dem Pümpgrunde der tiefen Rinne". CASPERS (1938) fand leere Gehäuse im Siebrest; bei eigenen Bodenfaunauntersuchungen seit 1949 kein lebendes Tier, nur leere Schalen gefunden. Doggerbank, englische Ostküsten, norwegische Küsten, Kattegat, von den Lofoten bis zu den Kanaren, Mittelmeer.

5 Lora turricula Montagu (Bela t. Montagu), Kleine turmförmige Treppenschnecke. (a) Mündungs-, (b) Rückansicht. Nicht selten in der Deutschen Bucht und in der Helgoländer Tiefen Rinne. Die Auswertung der qualitativen und quantitativen Bodenfaunauntersuchungen ab 1949 ergab, daß die Art sandige Gründe kaum besiedelt und schlick-sandige bis schlickige Böden bevorzugt. Nordsee, Kattegat, Limfjord, Ostsee bis Kieler Bucht. Nordatlantische Küsten Nordamerikas und Europas, nicht im Mittelmeer.

6 Mangelia costata Donovan (Pleurotoma $c$. Donovan).

(a) Mündungs-, (b) Rückseite. Englische Ostküste, norwegische, schwedische Küsten bis Bohuslän, Kattegat, Seeland. Europäische Atlantikkïisten von den britischen Westküsten bis ins Mittelmeer. 